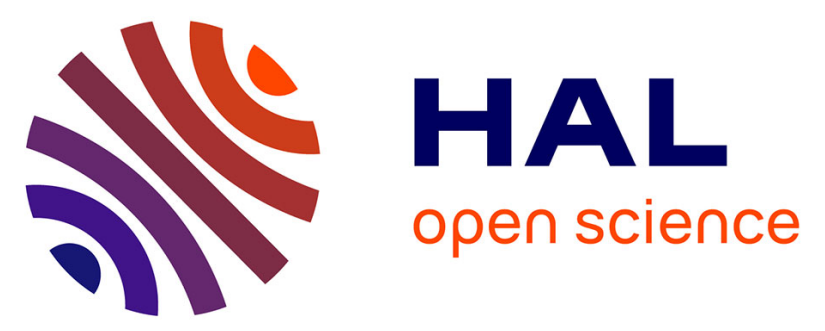

\title{
Fibroblast growth factor 23 decreases PDE4 expression in heart increasing the risk of cardiac arrhythmia; Klotho opposes these effects
}

\author{
Marta Lindner, Hind Mehel, Amandine David, Christine Leroy, Martine \\ Burtin, Gérard Friedlander, Fabiola Terzi, Delphine Mika, Rodolphe \\ Fischmeister, Dominique Prié
}

\section{To cite this version:}

Marta Lindner, Hind Mehel, Amandine David, Christine Leroy, Martine Burtin, et al.. Fibroblast growth factor 23 decreases PDE4 expression in heart increasing the risk of cardiac arrhythmia; Klotho opposes these effects. Basic Research in Cardiology, 2020, 115 (5), 10.1007/s00395-020-0810-6 . hal02940175

\section{HAL Id: hal-02940175 \\ https://hal.science/hal-02940175}

Submitted on 16 Sep 2020

HAL is a multi-disciplinary open access archive for the deposit and dissemination of scientific research documents, whether they are published or not. The documents may come from teaching and research institutions in France or abroad, or from public or private research centers.
L'archive ouverte pluridisciplinaire HAL, est destinée au dépôt et à la diffusion de documents scientifiques de niveau recherche, publiés ou non, émanant des établissements d'enseignement et de recherche français ou étrangers, des laboratoires publics ou privés. 
Fibroblast Growth Factor 23 decreases PDE4 expression in heart increasing the risk of cardiac arrhythmia, Klotho opposes these effects

Marta Lindner*, Hind Mehel ${ }^{*}$, Amandine David*, Christine Leroy*, Martine Burtin*, Gérard Friedlander*§†, Fabiola Terzi, Delphine Mika\#, Rodolphe Fischmeister\#, and Dominique Prié ${ }^{\star} \ddagger$

Running title: FGF23 and Klotho modify cardiomyocyte PDE expression

*INSERM U1151-CNRS UMR8253

§Université de Paris Faculté de Médecine

†Service de Physiologie Explorations Fonctionnelles Hôpital Européen Georges Pompidou, Assistance Publique- Hôpitaux de Paris

Université Paris-Saclay,Inserm U1180, 92296, Châtenay-Malabry, France

‡Service de Physiologie Explorations Fonctionnelles Hôpital Necker-Enfants Malades, Assistance Publique- Hôpitaux de Paris

Corresponding author: Pr Dominique Prié email : dominique.prie@inserm.fr 


\section{Abstract:}

Aims: The concentration of Fibroblast Growth Factor 23 (FGF23) rises progressively in renal failure (RF). High FGF23 concentrations have been consistently associated with adverse cardiovascular outcomes or death, in chronic kidney disease (CKD), heart failure or liver cirrhosis. We identified the mechanisms whereby high concentrations of FGF23 can increase the risk of death of cardiovascular origin.

Methods and Results: We studied the effects of FGF23 and Klotho in adult rat ventricular cardiomyocytes (ARVMs) and on the heart of mice with CKD. We show that FGF23 increases the frequency of spontaneous calcium waves (SCWs), a marker of cardiomyocyte arrhythmogenicity, in ARVMs. FGF23 increased sarcoplasmic reticulum $\mathrm{Ca}^{2+}$ leakage, basal phosphorylation of $\mathrm{Ca}^{2+}$ cycling proteins including phospholamban and ryanodine receptor type 2 . These effects are secondary to a decrease in phosphodiesterase 4B (PDE4B) in ARVMs and in heart of mice with RF. Soluble Klotho, a circulating form of the FGF23 receptor, prevents FGF23 effects on ARVMs by increasing PDE3A and PDE3B expression.

Conclusions: Our results suggest that the combination of high FGF23 and low sKlotho concentrations decreases PDE activity in ARVMs, which favors the occurrence of ventricular arrhythmias and may participate in the high death rate observed in patients with CKD.

Key words: Fibroblast growth factor 23, Klotho, Heart, Phosphodiesterases, Arrhythmia, Renal Failure 


\section{Declarations}

Funding sources: This work was supported by grants from the French agency Agence Nationale de la Recherche (CERF ANR- 13-BSV1-000201, EFIKAC ANR-16-CE14-0010) and Laboratory of Excellence GR-Ex (ANR- 11-LABX-0051, ANR-11-IDEX-0005-02) and LERMIT (ANR-10LABX-33, ANR-11-IDEX-0003-01).

Acknowledgements: We are grateful to David Bergerat (INSERM U1151CNRS UMR8253) and Florence Lefebvre (Inserm UMR-S 1180, Faculté de Pharmacie Université Paris-Saclay) for their skillful help in preparing cell cultures.

The manuscript does not contain clinical studies or patient data.

Conflict of interest: The authors declare that they have no conflict of interest.

\section{Introduction}

Fibroblast growth factor 23 (FGF23) is a hormone synthesized by osteoblasts and osteocytes. Its physiological role is to maintain phosphate and calcitriol concentrations within the normal range. Under physiological conditions the main target of FGF23 is the kidney. FGF23 increases phosphate excretion in urine by inhibiting the activity of the renal sodium-phosphate co-transporters 
[9]. FGF23 lowers calcitriol concentration by diminishing its synthesis, and by stimulating its degradation. The actions of FGF23 on the kidneys require the presence of a FGF receptor (FGFR) and aKlotho. aKlotho is a single pass trans-membrane glycoprotein of $130 \mathrm{kDa}$ expressed at the cell surface of renal cells also called membrane klotho (mKlotho). mKlotho associates to a FGFR to form the receptor for FGF23 [26]. A circulating form of aKlotho (soluble klotho or sKlotho) is released in the plasma. sKlotho is produced by the cleavage of mKlotho. The physiological role of sKlotho is still unclear.

At the early step of chronic kidney disease (CKD) FGF23 plasma concentration rises in order to maintain plasma phosphate concentration within normal values. Thus, blocking FGF23 effects by specific antibodies in animals with altered glomerular filtration rate augments phosphate, calcium and calcitriol plasma concentration and results in vascular calcifications $[17,48]$.

Regardless of the etiology, CKD is associated with an increased risk of death that augments exponentially as renal function declines [55]. Patients with CKD have a higher risk of dying prematurely than to progress to end-stage renal failure $(\mathrm{RF})$. The death is largely due to cardiovascular causes: sudden death, myocardial infarction, etc. The causes of these cardiovascular disorders in patients with CKD are multifactorial. Control of blood pressure and lipid abnormalities has limited effects on cardiovascular mortality in patients with RF suggesting that other mechanisms are involved. Understanding the mechanisms that contribute to these outcomes could help identifying new strategies to lower the risk of death of patients with RF. Elevated concentrations of FGF23 in RF have been repeatedly associated with cardiac hypertrophy, higher incidence of atrial fibrillation and an increased risk of death in clinical 
studies [30, 47, 52, 58]. High FGF23 concentration is the best predictor of the risk of death in patients with liver cirrhosis [40]. FGF23 levels are associated with poorer outcomes in patients with heart insufficiency $[15,20,21,25,29,39$, 53]. All these data suggest that FGF23 could have a deleterious effect on heart. It has been demonstrated that FGF23 caused pathological hypertrophy of isolated neonatal cardiomyocytes via activation of the calcineurin-NFAT pathway [11]. This effect was FGF receptor-dependent but independent of Klotho. It has been recently reported that FGF23 could favor spontaneous proarrhythmic $\mathrm{Ca}^{2+}$ events and that sKlotho could block this effect [34]. While all these data support a direct role of FGF23 on heart, the effects of FGF23 beyond the cardiac hypertrophy, and the mechanisms by which high FGF23 concentration could favor ventricular arrhythmias and sudden death are however largely unknown. The deletion of $\alpha$ Klotho gene in mice is associated with an increase in FGF23 plasma concentration and premature death of uncertain causes $[26,46]$. sKlotho concentration also decreases in the plasma of patients with CKD [26]. The consequences of the combination of high-FGF23 and low-sKlotho plasma concentrations on cardiomyocytes are unknown. The aim of this study was thus to further characterize the effects of FGF23 on adult rat ventricular myocytes (ARVMs), the mechanisms involved, and to determine the role of sKlotho on ARVMs.

\section{Methods}

A detailed description of the methods is presented in the Electronic Supplementary Material. 
All experiments were carried out according to the European Community guiding principles in the care and use of animals (2010/63/UE, 22 September 2010), the local Ethics committee (CEEA26 CAPSud) guidelines and the French decree $n^{\circ} 2013-118,1^{\text {st }}$ February 2013 on the protection of animals used for scientific purposes (JORF $n^{\circ} 0032,7$ February 2013 p2199, text $\left.n^{\circ} 24\right)$. Animal experiments were approved by the French Ministry of Agriculture (prefectural agreement $\mathrm{N}^{\circ} 2016-108$ and agreement to our animal facility $\mathrm{N}^{\circ} \mathrm{C}$ 92-019-01).

Isolation and culture of ARVMs. Male Wistar rats (250-300 mg) were anesthetized by intraperitoneal injection of dolethal $(150 \mathrm{mg} / \mathrm{kg})$ and the hearts were excised rapidly from anaesthetized male Wistar rats (250-300 mg). Individual ARVMs were obtained by retrograde perfusion through the ascending aorta using Langendorff apparatus as described previously[54]. The method used to isolate ARVM is detailed in Supplementary Material.

Production of FGF23 and sKlotho. Human recombinant FGF23 was purchased from R\&D Systems (Minneapolis USA). FGF23 concentration was determined using the iFGF23 immuno-chemi- luminescent sandwich assay developed by DiaSorin (Saluggia, Italy) as previously described[50].

HEK cells were stably transfected with a plasmid encoding amino acid 1 to 986 that represents the circulating or soluble form of aKlotho (sKlotho). sKlotho was released in the supernatant, the size of the protein was controlled by western blot. The concentration of sKlotho was determined with the IBL Elisa kit (Human soluble a-Klotho Assay Kit code No. 27998 - IBL, Japan). 
CAMP measurements by FRET. ARVMs were infected with an adenovirus encoding the Epac-S ${ }^{\mathrm{H} 187}$ cAMP-FRET probe (kindly provided by Dr. Kees Jalink, Cancer Institude, Amsterdam, Netherlands[24]) for 48h. Changes in cAMP levels were assessed by YFP/CFP (yellow fluorescent protein/cyan fluorescent protein) emission ratios.

ICa,L current measurements. $L$ type $\mathrm{Ca}^{2+}$ current was recorded in the wholecell configuration of the patch-clamp technique as previously described[54]. Currents were not compensated for capacitance and leak currents. All experiments were performed at room temperature.

Measurements of SR $\mathbf{C a}^{2+}$ leak and load. Isolated ARVMs were loaded with $1 \mu \mathrm{M}$ Fura-2-AM (Invitrogen, Carlsbad, CA, USA). Calcium transient was recorded with Fura-2 ratios (IonOptix) as described previously[28]. Myocytes were stimulated at a frequency of $0.5 \mathrm{~Hz}$. SR $\mathrm{Ca}^{2+}$ leak and load were measured as previously described [49].

Immunoblot Analysis. Protein samples were prepared from ventricular myocytes. Samples were separated in denaturizing acrylamide gels and transferred ontro nitrocellulose or PVDF membranes. After blocking the membranes with skimmed milk (5\%) for $1 \mathrm{~h}$, the incubation with appropriate antibodies was performed over night at $4^{\circ} \mathrm{C}$. After three washes with TBST, blots were incubated with appropriate peroxidase-conjugated antibodies for 1 h. Antibody binding was visualized using enhanced chemiluminescence 
(Thermo Scientific Waltham, MA, USA) and quantified with Quantity One software (Biorad, Hercules, CA, USA).

Real time quantitative RT-PCR analysis of mRNA. RNA was extracted from heart samples with trizol (Invitrogen, Carlsbad, CA, USA), reverse-transcribed into cDNA (iScript cDNA Synthesis Kit, Biorad Hercules, CA, USA), and mRNA abundance was analyzed by real-time PCR with SYBR-green (SYBR Green/ROX qPCR, Master Mix, Fermentas, Waltham, MA, USA). Details of primers are provided in Supplementary Table 1.

Mouse experiments. All experiments were performed on 9-week-old FVB/N mice from (Janvier's Labs, Le Genest-Saint Isle, France) subjected to $75 \%$ nephrectomy or sham-operation and sacrificed 8 weeks after surgery. Surgery and euthanasia of animals were performed under general anesthesia by intraperitoneal injection of ketamine $(160 \mathrm{mg} / \mathrm{kg})$ and xylazine $(8 \mathrm{mg} / \mathrm{kg})$. At the time of sacrifice urine and plasma were collected and the kidney and heart were removed and frozen in liquid nitrogen.

Circulating mouse FGF23 concentrations were measured in duplicate using an ELISA assay (Immutopics International, San Clemente, CA, USA), according to the manufacturers protocol.

Statistical analysis. The tests used to assess statistical significance are mentioned for each experiment in the legend of the figures or in the text. All the 
results are expressed as mean $( \pm S E M)$. Differences with $p$-values $<0.05$ were considered as statistically significant.

\section{Results}

Effects of FGF23 and sKlotho on SCWs. Because ventricular arrhythmia is a frequent cause of death in patients with RF, we checked if incubation of ARVMs with FGF23 at a concentration of $6 \mathrm{ng} / \mathrm{ml}$, a level commonly observed in patients with RF, could promote SCWs, a marker of arrhythmic events. $\mathrm{Ca}^{2+}$ transients were recorded in ARVMs cultivated for $24 \mathrm{~h}$ with a control medium or FGF23 and subsequently loaded with the calcium indicator Fura-2 and stimulated at a pace of $0.5 \mathrm{~Hz}$ in the presence of isoprenaline (ISO 1 or $10 \mathrm{nM}$; Table 1 and supplementary Figure $1 \mathrm{~A}$ ). We assessed the number of cells with SCWs during a 3-min recording. In the absence of FGF23, $1 \mathrm{nM}$ ISO did not induce SCWs (Table 1 and supplementary Figure 1). By contrast $45.8 \%$ of ARVMs treated with FGF23 exhibited SCWs in the presence of $1 \mathrm{nM} \mathrm{ISO} \mathrm{(Table}$ 1 and supplementary Figure 1). Raising ISO concentration to $10 \mathrm{nM}$ induced SCWs in $62.5 \%$ of ARVMs treated with control medium, and treatment with FGF23 further increased the number of ARVMs presenting SCWs to $95.0 \%$ (Table 1). Incubation of ARVMs with sKlotho decreased the number of cells with SCWs thus preventing the FGF23 effect (Table 1). Unexpectedly in the absence of FGF23, sKlotho alone also decreased the number of cells with SCWs induced by $10 \mathrm{nM}$ of ISO to $41.1 \%$ (Table 1 ). 


\section{Effects of FGF23 on SR $\mathrm{Ca}^{2+}$ leak, SR $\mathrm{Ca}^{2+}$ load and phosphorylation of}

$\mathrm{Ca}^{2+}$ handling proteins. Because ISO-induced arrhythmias are largely due to an increased diastolic $\mathrm{Ca}^{2+}$ leak from the SR via RyR2, we measured $\mathrm{Ca}^{2+}$ leakage using a $\mathrm{Na}^{+} / \mathrm{Ca}^{2+}$-free Tyrode solution $\left(0 \mathrm{Na}^{+} / 0 \mathrm{Ca}^{2+}\right.$ solution) to prevent $\mathrm{Ca}^{2+}$ extrusion by the $\mathrm{Na}^{+} / \mathrm{Ca}^{2+}$ exchanger $(\mathrm{NCX})$ and tetracaine $(1 \mathrm{mM})$ to block RyR2. Application of caffeine $(10 \mathrm{mM})$ at the end of the experiment was used to evaluate SR $\mathrm{Ca}^{2+}$ load. FGF23 treatment drastically increased SR $\mathrm{Ca}^{2+}$ leak (Figure $1 \mathrm{~A}$ and $\mathrm{B}$ ), whereas it did not modify SR $\mathrm{Ca}^{2+}$ load (Figure $1 \mathrm{C}$ ). To analyze the presence of SCWs, cells were briefly exposed to $0 \mathrm{Na}^{+} / 0 \mathrm{Ca}^{2+}$ solution and SCWs were recorded during a 20s pacing pause. Cardiomyocytes treated with FGF23 showed more occurrences of SCWs than control cells (Figure 1D and 1E) suggesting pro-arrhythmogenic effects of FGF23 on the heart. To determine the molecular mechanisms of the increased SR $\mathrm{Ca}^{2+}$ leak, we analyzed the phosphorylation level of two key $\mathrm{Ca}^{2+}$-handling proteins by immunoblot: PLB and RyR2. A 24h-incubation of ARVMs with FGF23 significantly increased phosphorylation at Serine 16 and Threonine 17 of PLB and at Serine 2808 and 2814 of RyR (Figures 2A and 2C). These results indicate that both protein kinase $\mathrm{A}(\mathrm{PKA})$ and $\mathrm{Ca}^{2+} /$ calmodulin-dependent protein kinase II (CaMKII) are activated by FGF23 treatment. Co-incubation of FGF23 and sKlotho prevents the FGF23-induced phosphorylation of PLB and RyR2 (Figures 2B and 2D).

FGF23 decreases PDE4 expression and increases ISO-induced cAMP levels. Since FGF23 increases and sKlotho decreases SCW frequency induced by ISO (Table 1) and FGF23 increases PLB and RyR2 phosphorylation 
(Figure 2), we checked if FGF23 and sKlotho could affect [cAMP]i accumulation in ARVMs in response to ISO stimulation. We measured real-time changes of ISO-induced [CAMP]i in ARVMs infected with an adenovirus expressing the FRET-based cAMP probe Epac-S ${ }^{H 187}$. ARVMs were incubated for $24 \mathrm{~h}$ with control medium, FGF23, sKlotho alone or FGF23 in combination with sKlotho. The cells were then challenged with a short application of ISO (30 nM, $15 \mathrm{~s}$, Figure $3 \mathrm{~A}, \mathrm{~B}$ and $\mathrm{C})$. Maximal [cAMP]i accumulation in response to a $15 \mathrm{sec}$ application of ISO was significantly higher (Figure $3 \mathrm{~A}$ and $\mathrm{C}$ ) and the decay kinetic, which reflects cAMP hydrolysis by PDEs[22], was slower (Figure 3B) in FGF23 treated than in control ARVMs. ARVMs express FGR1, FGFR3 and FGFR4 (supplementary Figure 3D). In heart FGF23 can stimulate the calcineurin/NFAT pathway. To determine if this pathway could mediate FGF23 effect on $[\mathrm{CAMP}] \mathrm{i}$ in response to ISO we inhibited calcineurin stimulation with CspA. CspA alone did not modify ISO-induced [cAMP]i level (Figure 3A and C). However, in the presence of CspA FGF23 did not enhance ISO-induced [cAMP]i accumulation (Figure $3 \mathrm{~A}$ and $\mathrm{C}$ ). Next we determined the effect of sKlotho alone or in combination with FGF23 on $\beta-A R$ induced [CAMP]i. sKlotho prevented the amplification of ISO-induced [CAMP]i accumulation by FGF23 (Figure $3 A$ and $C$ ).

To further characterize the mechanisms by which FGF23 could interfere with ISO-induced cAMP accumulation we assessed by western blotting the expression of the main cAMP-specific PDE isoforms expressed in ARVMs. FGF23 specifically decreased PDE4B expression (Figure 3D and E). PDE3A, PDE3B and PDE4A protein expression were unchanged by FGF23 treatment (Figure 3D and E). Next, we determined PDEs mRNA levels by quantitative 
reverse-transcription polymerase chain reaction (qRT-PCR) and we found about 5-fold lower level of PDE4B in ARVMs treated with FGF23 compared with cells treated with control medium, indicating that changes in PDE4B expression induced by FGF23 take place at the transcriptional level (Figure 3F). To determine if the decrease in PDE4B expression was specific of FGF23 or secondary to cardiac hypertrophy we used FGF2 as a control. FGF2 alone, which increased ARVMs surface area (Supplementary Figure 2B), did not modify the expression of PDE4B nor that of PDE3A, 3B and 4A (Figure 4A). This confirms that the decrease in PDE4B expression was specifically induced by FGF23 and not a consequence of ARVMs hypertrophy. Incubation of ARVMs with sKlotho or CspA in combination with FGF23 completely prevented the effect of FGF23 on PDE4B expression (Figure 4B, 4C and 4D).

To determine the contribution of different pathways to PDE4B regulation by FGF23 in ARVMs, we analyzed the phosphorylation pattern of Extracellular Signal-regulated Kinase (ERK), Phospholipase $\mathrm{CY}_{\mathrm{Y}}(\mathrm{PLC} \mathrm{C})$ and serine/threonine kinase (Akt) after acute (15 min) or 24h stimulation with FGF23. We used ARVMs treated for 10 min with phenylephrine (Phe, $50 \mu \mathrm{M}$ ) as positive control. Exposition of ARVMs with FGF23 for 15 min did not modify Akt phosphorylation (Figure 5A) while a 24h incubation significantly decreased the phosphorylation level of Akt (Figure 5B). Moreover, FGF23 increased phosphorylation of PLCY1 within 15 min of treatment without changing overall PLCY1 expression (Figure 5C) but a 24h-exposition with FGF23 did not affect PLCy1 phosphorylation (Figure 5D). FGF23 did not change the level of ERK phosphorylation after acute stimulation and after a $24 \mathrm{~h}$ of treatment (Figure $6 \mathrm{~A}, 6 \mathrm{~B}$ and $6 \mathrm{C}$ ). 
Effects of FGF23 on excitation-contraction coupling. We tested whether the decrease in PDE4B expression induced by FGF23s modified the $\beta$-AR regulation of excitation-contraction coupling. First, we analyzed the L-type calcium current amplitude ( $\left.\mathrm{I}_{\mathrm{Ca}, \mathrm{L}}\right)$ by the whole cell patch clamp technique. FGF23 significantly increased basal I $\mathrm{Ca}_{\mathrm{a}, \mathrm{L}}$ density (Figure $7 \mathrm{C}, 7 \mathrm{D}$ and 7F). The response to a pulse application of ISO (30 nM, $15 \mathrm{~s})$ was markedly increased by FGF23 treatment (Figure 7A, 7B and 7E). However, co-incubation of cardiomyocytes with FGF23 and either CspA, or FGFR antagonist PD173074, or sKlotho restored a normal response to ISO (Figure 7).

\section{Effects of sKlotho on PDEs expression levels and $\mathrm{Ca}^{2+}$-handling proteins.}

We further characterized the effects of sKlotho on ARVMs. We first verified by qRT-PCR and western blot that ARVMs did not express aKlotho (data not shown). Since sKlotho alone decreases the percentage of ARVMs exhibiting SCWs in response to ISO (Table 1) and prevents the actions of FGF23 on basal phosphorylation level of PLB and RyR2 (Figure 2B), [CAMP]i accumulation (Figure 3A, B and C) and $\mathrm{I}_{\mathrm{Ca}, \mathrm{L}}$ amplitude (Figure 7E and 7F), we checked if sKlotho could modify the expression of PDEs. Incubation of ARVMs with sKlotho $(0.95 \mathrm{ng} / \mathrm{ml}$, a concentration within the normal range in human[45],[38] for $24 \mathrm{~h}$ ) increased the expression of PDE3A and PDE3B at the protein level (respectively by $\sim 60 \%$ and $\sim 30 \%$, western blot Figure $8 \mathrm{~A}$ ) as well as at the mRNA level (respectively by $\sim 7$-fold and 9-fold, qRT-PCR Supplementary Figure 3B). sKlotho did not modify the expression of PDE4A and PDE4B (Supplementary Figure $3 \mathrm{~A}$ and $\mathrm{B}$ ). Co-incubation of cardiomyocytes with 
FGF23 and sKlotho did not modify the expression level of PDEs (Figure 8B). sKlotho alone decreased the phosphorylation level of PLB and RyR2 at both PKA and CAMKII phosphorylation sites (Figure $8 \mathrm{C}$ ) resulting in a decreased number of cells exhibiting SCWs in response to ISO (Table 1).

sKlotho did not modify transient receptor potential cation channels (TRPC6) or SR $\mathrm{Ca}^{2+}$-ATPase (SERCA2a) expressions (Supplementary Figure 3C) nor phosphorylation level of ERK (Figure 6C).

\section{Subtotal nephrectomy induces cardiac hypertrophy and modifies PDE4B}

expression. To determine if the FGF23-induced modifications of PDE expression observed in ARVMs in culture were relevant in a model of CKD we studied mice submitted to $75 \%$ excision of total renal mass $(\mathrm{Nx})$. Mean values of body, kidney, or heart weight, creatinine and proteinuria levels and urine excretion of $\mathrm{Na}^{+}, \mathrm{K}^{+}$and $\mathrm{Ca}^{2+}$ in sham-operated and $\mathrm{Nx}$ mice are presented in Supplementary Table 2. As expected, plasma creatinine concentration and urinary protein, two markers of renal function were significantly increased in $\mathrm{Nx}$ mice as compared to the Sham group (Figure 9A, Supplementary Table 2) indicating glomerular injury. Nx animals also exhibited cardiac hypertrophy (Figure 9B). Plasma FGF23 concentration measured six weeks after surgery was higher in Nx mice than in Sham animals (Figure 9C). To test whether elevated FGF23 plasma concentrations observed in CKD could modify cardiac PDEs levels, we assessed by western blotting the expression of the main cAMP-specific PDE isoforms in the heart. We observed that PDE4B expression was specifically reduced in Nx mice as compared to the Sham group ( 2 fold, Figure 9E). Consistently the level of PDE4B mRNA was lower in the heart of 
$\mathrm{Nx}$ animals than in Sham mice (Figure 9D). The impact of the Nx on PDE4B was specific since neither the mRNA, nor the protein level of PDE3A, PDE3B and PDE4A changed in the heart after the Nx.

\section{Discussion}

While it is known that a high concentration of FGF23 can induce hypertrophy and have deleterious effects on heart function, the mechanisms by which FGF23 alters cardiomyocyte physiology remain largely unknown [14]. Our results unveil some of these mechanisms. We show that treatment with FGF23 increases the number of SCWs in ARVMs in response to ISO. We observed that FGF23 increased RyR2 and PLB phosphorylation at PKA and CaMKII sites, modifications that are known to augment SR $\mathrm{Ca}^{2+}$ leak. There is strong evidence that increased diastolic $\mathrm{Ca}^{2+}$ leak from the $\mathrm{SR}$ via RyR2, increases occurrence of SCWs via activation of the electrogenic $\mathrm{Na}^{+} / \mathrm{Ca}^{2+}$-exchanger, causing delay after depolarizations which are able to trigger action potentials, increasing the risk of ventricular arrhythmia [3]. Increased CaMKII phosphorylation of S2814 on RyR2 was shown to play a critical role in the development of ventricular arrhythmias even in the absence of structural heart disease $[37,41]$. Our findings that FGF23 increases the number of SCWs in cardiomyocytes by acute $\beta$-AR stimulation due to increased $\mathrm{SR} \mathrm{Ca}^{2+}$ leak and higher RyR2-S2814 phosphorylation are in agreement with these observations. Recently Novarro-Garcia et al reported similar results [34]. They observed that FGF23 induced RyR phosphorylation at the CaMKII site resulting in an increase in $\mathrm{Ca}^{2+}$ spark frequency that could trigger pro-arrhythmogenic events. Our data identify the mechanisms involved in FGF23 effect on ARVM. 
We report for the first time that FGF23 specifically inhibits PDE4B expression. PDE4B is a cAMP-specific PDE and one of the main isoforms of PDEs expressed in rodent cardiomyocytes. It plays a central role in the control of cAMP signaling in response to $\beta$-AR stimulation and is associated with the L-type calcium channels $[8,31,54]$. PDE4 is also expressed in human heart and is involved [33] in the generation of cAMP compartments by forming barriers for cAMP diffusion or acting as local sink for cAMP [23, 27, 42, 43] . We observed that a $24 \mathrm{~h}$ exposure of ARVMs to FGF23 specifically decreased the expression of PDE4B, and that this effect was abolished when the calcineurin/NFAT pathway was inhibited by CspA. Abi-Gerges et al. reported a decreased expression and activity of PDE4B in cardiac hypertrophy [1]. However, the decrease in PDE4B expression induced by FGF23 was not due to ARVMs hypertrophy per se since FGF2, which had similar effects on ARVMs size as FGF23, did not modify PDE expression. The decrease in PDE4B expression resulted in an increase in ISO-induced [cAMP]i accumulation, PLB and RyR2 phosphorylations, Ica,L amplitude, calcium transients and sarcomere shortening. These results parallel those obtained by Bobin et al, who showed similar effects in ARVMs with a selective PDE4 inhibitor [4]. Our findings also mimic those obtained in cardiomyocytes from PDE4B-/- mice where $\mathrm{Ca}^{2+}$ transients, cell contraction, and spontaneous $\mathrm{Ca}^{2+}$ release events under $\beta$ adrenergic stimulation were increased by comparison with wild-type cardiomyocytes [28]. Leroy et al. also reported in in vivo experiments that the percentage of mice with ventricular tachycardia after ISO infusion and a burst pacing was significantly higher in $\mathrm{PDE}^{-/-}$mice than in wild type. We observed that PDE4B inhibition by FGF23 also significantly augments sarcomere 
shortening and $\mathrm{Ca}^{2+}$ transient in the absence of ISO stimulation. These results are similar to the results obtained by Cilvik et al., who showed that ventricular myocytes from FGFR1-transgenic mice have enhanced contraction suggesting that activation of FGF signaling pathway in cardiomyocytes increases contractility and results in a hypertrophic cardiomyopathy [7]. In addition, we showed that PDE4B is decreased at protein and transcriptional level in mice subjected to subtotal nephrectomy. Altogether, our data demonstrate that the reduction in PDE4B expression induced by FGF23 has functional consequences which may contribute to the increased risk of ventricular arrhythmia responsible for sudden death in patients with RF. Blocking these effects of FGF23 could decrease the death rate in CKD patients.

Our data show that the effects of FGF23 on cardiomyocytes are mediated by a FGFR. Indeed, FGFR antagonists prevented all the effects of FGF23 on cardiomyocytes. Although the affinity of FGF23 for FGFR is low, at the high concentrations as observed in patients with RF, FGF23 is able to stimulate the calcineurin/NFAT pathway via a FGFR in the absence of aKlotho [11]. We showed that a short exposition of ARVMs to FGF23 increases phosphorylated PLCY level. This finding is supported by studies of Grabner et al and Han et al [13][16] who showed that FGF23 activates cardiotoxic PLCY signaling pathway and induces cardiac hypertrophic growth in vivo and in vitro via FGFR4 in the absence of co-expression of $\alpha$-Klotho. A 24h FGF23 treatment decreased the amount of phosphorylated Akt. FGF23-induced changes in PLCY and/or Akt activation could mediate other FGF23 effects on ARVMs beyond cardiac hypertrophy including decrease in PDE4B expression. 
The mechanism by which FGF23 decreases PDE4B expression and the role of PLCy and Akt signaling will require further investigations.

We also studied the role of sKlotho on ARVMs in the presence or in the absence of FGF23. Although the role of aKlotho as a FGF23 co-receptor is established, the role of the circulating form of Klotho is still largely unclear. We report here that sKlotho. can modify cardiomyocytes functions via two mechanisms: by interfering with FGF23 action, it prevents FGF23-induced PDE4B decreases, and by acting alone in the absence of FGF23, it increases PDE3A and 3B expression. Klotho can modulate TRPC6 activity in the absence of FGF23 or FGFR in cardiomyocytes or in a myoblast cell line [56] [57]. Klotho also modifies KCNQ1/KCNE1 $\mathrm{K}+$ channels stability when expressed in Xenopus oocytes [2]. sKlotho can modify the activity of various ion channels and Na-phosphate cotransporters [18], and can bind to Wnt ligands [5, 19, 57]. We report here that sKlotho can also prevent the decrease in PDE4B expression induced by FGF23. Several mechanisms can be involved. It has been recently reported that sKlotho can form a complex with a FGFR and FGF23 that can activate the phosphorylation of the ERK pathway in HEK293 cells[6]. While the possibility of formation of a complex between sKlotho, FGF23 and a FGFR in ARVMs would require further investigation, we did not observe phosphorylation of ERK in the presence of FGF23 and sKlotho at concentrations that prevent FGF23 effects on ARVMs. Alternatively, sKlotho could prevent the association of FGF23 to FGFR preventing the activation of the NFAT pathway.

We also show that not only sKlotho interferes with FGF23 actions, but it also increases the expression of PDE3A and PDE3B in the absence of FGF23. 
It has been reported that sKlotho can interfere with phosphoinositide 3-kinase (PI3K) signaling triggered by IGF1 in cardiomyocytes [57]. PI3Ky can associate with PDE3 and increase its activity but not its expression [12]. The mechanisms by which sKlotho increases PDE3 expression and the potential role of PI3K signaling in this matter will require further investigations.

PDE3 is a major regulator of cAMP in cardiomyocytes and was shown to regulate cardiac contractility by modulating PLB-SERCA2 activity and subsequent sarcoplasmic reticulum $\mathrm{Ca}^{2+}$ uptake[44]. Moreover PDE3 might be also important in pathological cardiac remodeling, for example decreased PDE3A expression has been found in diseased hearts in rodents [1]. Some studies showed that the inhibition of PDE3 activity or knockdown of PDE3 expression was associated with myocyte apoptosis [10]. Recent study demonstrated that myocardial overexpression of PDE3A in transgenic mice leads to a decrease in heart rate and myocardial contractile function through attenuating PKA-mediated troponin I phosphorylation and can protect the heart against cardiac ischemia/reperfusion injury [36]. Our findings suggest that a decrease in PDE3 expression could participate in the enhanced ISO-induced hypertrophy observed in Klotho deficient mice.

Low levels of circulating Klotho concentration are inconstantly associated to the risk of atrial fibrillation in patients with end stage renal disease [35][32]. Our results could give an explanation for these differences between studies. High concentrations of FGF23 markedly decrease PDE4B expression that favor arrhythmogenic effects as reported here. Observing an additional effect due to the decline in sKlotho is challenging and could be influenced by 
the characteristics of the populations studied such as FGF23 levels, the distribution and levels of sKlotho concentration...

Klotho is not present in ventricular myocytes but is detected in the sinoatrial node [51]. It is unknown if this form of Klotho is similar to sKlotho. It has been reported that Isolated sino-atrial nodes of mice with Klotho gene disruption are dysfunctional. The mechanisms by which Klotho expressed in nodal cells modifies their function remain to be elucidated.

\section{Conclusions}

This study unveils the mechanisms by which the high concentrations of FGF23 associated to low sKlotho concentration in the plasma have deleterious effects on the heart of patients with CKD. FGF23 decreases PDE4B by stimulating the calcineurin/NFAT pathway via the activation of a FGFR. This results in an

increase in $\mathrm{Ca}^{2+}$ leakage and basal phosphorylation levels of $\mathrm{Ca}^{2+}$-cycling proteins including PLB and RyR2 leading to the higher occurrence of SCWs. We show that FGF23 increases [CAMP]i levels, basal and ISO-induced ICa,L amplitude, and calcium transients. All these effects are prevented in the presence of sKlotho that increases PDE3A and PDE3B expressions. PDE4 is expressed in human myocardium and its inhibition has been shown to induce arrhythmias in human atrium. Our data suggest that inhibition of PDE4 expression[33] could also participate in the increase rate of sudden death mainly due to ventricular arrhythmia in disorders with high FGF23 concentration and/or low sKlotho levels as observed in renal insufficiency and heart failure. 


\section{References}

1. Abi-Gerges A, Richter W, Lefebvre F, Mateo P, Varin A, Heymes C, Samuel JL, Lugnier C, Conti M, Fischmeister R, Vandecasteele G (2009) Decreased expression and activity of cAMP phosphodiesterases in cardiac hypertrophy and its impact on $\beta$-Adrenergic cAMP signals. Circ Res 105:784-792. doi: 10.1161/CIRCRESAHA.109.197947

2. Almilaji A, Pakladok T, Muñoz C, Elvira B, Lang F, Almilaji A, Pakladok T, Muñoz C, Elvira B, Almilaji A, Pakladok T, Muñoz C, Elvira B, Sopjani M, Lang F (2014) Upregulation of KCNQ1 / KCNE1 K channels by Klotho Upregulation of KCNQ1 / KCNE1 K + channels by Klotho. 6950. doi: 10.4161/chan.27662

3. Bers DM (2014) Cardiac Sarcoplasmic Reticulum Calcium Leak: Basis and Roles in Cardiac Dysfunction. Annu Rev Physiol 76:107-127. doi: 10.1146/annurev-physiol-020911-153308

4. Bobin P, Varin A, Lefebvre F, Fischmeister R, Vandecasteele G, Leroy J (2016) Calmodulin kinase II inhibition limits the pro-Arrhythmic Ca2+waves induced by camp-phosphodiesterase inhibitors. Cardiovasc Res 110:151-161. doi: 10.1093/cvr/cvw027

5. Buendía P, Ramírez R, Aljama P, Carracedo J (2016) Klotho Prevents Translocation of NFkB. In: Vitamins and Hormones. pp 119-150

6. Chen G, Liu Y, Goetz R, Fu L, Jayaraman S, Hu M-C, Moe OW, Liang G, Li X, Mohammadi M (2018) $\alpha$-Klotho is a non-enzymatic molecular scaffold for FGF23 hormone signalling. Nature 553:461-466. doi: $10.1038 /$ nature25451

7. Cilvik SN, Wang JI, Lavine KJ, Uchida K, Castro A, Gierasch CM, 
Weinheimer CJ, House SL, Kovacs A, Nichols CG, Ornitz DM (2013)

Fibroblast growth factor receptor 1 signaling in adult cardiomyocytes increases contractility and results in a hypertrophic cardiomyopathy. PLoS One 8:1-17. doi: 10.1371/journal.pone.0082979

8. Conti M, Richter W, Mehats C, Livera G, Park JY, Jin C (2003) Cyclic AMP-specific PDE4 phosphodiesterases as critical components of cyclic AMP signaling. J Biol Chem 278:5493-5496. doi:

10.1074/jbc.R200029200

9. Courbebaisse M, Lanske B (2017) Biology of Fibroblast Growth Factor 23 : From physiology to pathology. Cold Spring Harb Perspect Med

10. Ding B, Abe JI, Wei H, Huang Q, Walsh RA, Molina CA, Zhao A, Sadoshima J, Blaxall BC, Berk BC, Yan C (2005) Functional role of phosphodiesterase 3 in cardiomyocyte apoptosis: Implication in heart failure. Circulation 111:2469-2476. doi:

\subsection{1/01.CIR.0000165128.39715.87}

11. Faul C, Amaral AP, Oskouei B, Hu M-CC, Sloan A, Isakova T, Gutiérrez OM, Aguillon-Prada R, Lincoln J, Hare JM, Mundel P, Morales A, Scialla J, Fischer M, Soliman EZ, Chen J, Go AS, Rosas SE, Nessel L, Townsend RR, Feldman HI, St. John Sutton M, Ojo A, Gadegbeku C, Di Marco GS, Reuter S, Kentrup D, Tiemann K, Brand M, Hill JA, Moe OW, Kuro-o M, Kusek JW, Keane MG, Wolf M, Gutierrez OM, AguillonPrada R, Lincoln J, Hare JM, Mundel P, Morales A, Scialla J, Fischer M, Soliman EZ, Chen J, Go AS, Rosas SE, Nessel L, Townsend RR, Feldman HI, St John Sutton M, Ojo A, Gadegbeku C, Di Marco GS, Reuter S, Kentrup D, Tiemann K, Brand M, Hill JA, Moe OW, Kuro OM, 
Kusek JW, Keane MG, Wolf M, Guti??rrez OM, Aguillon-Prada R, Lincoln J, Hare JM, Mundel P, Morales A, Scialla J, Fischer M, Soliman EZ, Chen J, Go AS, Rosas SE, Nessel L, Townsend RR, Feldman HI, Sutton MSJ, Ojo A, Gadegbeku C, Di Marco GS, Reuter S, Kentrup D, Tiemann K, Brand M, Hill JA, Moe OW, Kuro-o M, Kusek JW, Keane MG, Wolf M (2011) FGF23 induces left ventricular hypertrophy. J Clin Invest 121:4393-4408. doi: 10.1172/jci46122

12. Ghigo A, Perino A, Mehel H, Zahradníková A, Morello F, Leroy J, Nikolaev VO, Damilano F, Cimino J, De Luca E, Richter W, Westenbroek R, Catterall WA, Zhang J, Yan C, Conti M, Gomez AM, Vandecasteele G, Hirsch E, Fischmeister R (2012) Phosphoinositide 3kinase $\mathrm{y}$ protects against catecholamine-induced ventricular arrhythmia through protein kinase A-mediated regulation of distinct phosphodiesterases. Circulation 126:2073-2083. doi:

10.1161/CIRCULATIONAHA.112.114074

13. Grabner A, Amaral AP, Schramm K, Singh S, Sloan A, Yanucil C, Li J, Shehadeh LA, Hare JM, David V, Martin A, Fornoni A, Di Marco GS, Kentrup D, Reuter S, Mayer AB, Pavenstädt H, Stypmann JJ, Kuhn C, Hille S, Frey N, Leifheit-Nestler M, Richter B, Haffner D, Abraham R, Bange J, Sperl B, Ullrich A, Brand M, Wolf M, Faul C, Pavenst??dt H, Stypmann JJ, Kuhn C, Hille S, Frey N, Leifheit-Nestler M, Richter B, Haffner D, Abraham R, Bange J, Sperl B, Ullrich A, Brand M, Wolf M, Faul C (2015) Activation of Cardiac Fibroblast Growth Factor Receptor 4 Causes Left Ventricular Hypertrophy. Cell Metab 22:1020-1032. doi: 10.1016/j.cmet.2015.09.002 
14. Grabner A, Faul C (2016) The role of fibroblast growth factor 23 and Klotho in uremic cardiomyopathy. 25:314-324. doi:

10.1097/MNH.0000000000000231

15. Gruson D, Lepoutre T, Ketelslegers J-M, Cumps J, Ahn SA, Rousseau MF (2012) C-terminal FGF23 is a strong predictor of survival in systolic heart failure. Peptides 37:258-262. doi: 10.1016/j.peptides.2012.08.003

16. Han X, Cai C, Xiao Z, Quarles LD (2020) Journal of Molecular and Cellular Cardiology FGF23 induced left ventricular hypertrophy mediated by FGFR4 signaling in the myocardium is attenuated by soluble Klotho in mice. J Mol Cell Cardiol 138:66-74. doi:

10.1016/j.yjmcc.2019.11.149

17. Hasegawa H, Nagano N, Urakawa I, Yamazaki Y, lijima K, Fujita T, Yamashita T, Fukumoto S, Shimada T (2010) Direct evidence for a causative role of FGF23 in the abnormal renal phosphate handling and vitamin $\mathrm{D}$ metabolism in rats with early-stage chronic kidney disease. Kidney Int 78:975-980. doi: 10.1038/ki.2010.313

18. Hu MC, Shi M, Zhang J, Pastor J, Nakatani T, Lanske B, Razzaque MS, Rosenblatt KP, Baum MG, Kuro-o M, Moe OW Klotho : a novel phosphaturic substance acting as an autocrine enzyme in the renal proximal tubule. doi: 10.1096/fj.10-154765

19. Huang C (2010) Regulation of ion channels by secreted Klotho : mechanisms and implications. Kidney Int 77:855-860. doi: 10.1038/ki.2010.73

20. Isakova T, Houston J, Santacruz L, Schiavenato E, Somarriba G, Harmon WG, Lipshultz SE, Miller TL, Rusconi PG (2013) Associations 
between fibroblast growth factor 23 and cardiac characteristics in pediatric heart failure. Pediatr Nephrol 28:2035-2042. doi:

$10.1007 / \mathrm{s} 00467-013-2515-7$

21. Ix JH, Katz R, Kestenbaum BR, De Boer IH, Chonchol M, Mukamal KJ, Rifkin D, Siscovick DS, Sarnak MJ, Shlipak MG (2012) Fibroblast growth factor-23 and death, heart failure, and cardiovascular events in community-living individuals: CHS (Cardiovascular Health Study). J Am Coll Cardiol 60:200-207. doi: 10.1016/j.jacc.2012.03.040

22. Jérôme L, Aniella A-G, O. NV, Wito R, Patrick L, Jean-Luc M, Marco C, Rodolphe F, Grégoire V (2008) Spatiotemporal Dynamics of $\beta$ Adrenergic cAMP Signals and L-Type Ca2+ Channel Regulation in Adult Rat Ventricular Myocytes. Circ Res 102:1091-1100. doi: 10.1161/CIRCRESAHA.107.167817

23. Jurevičius J, Skeberdis VA, Fischmeister R (2003) Role of cyclic nucleotide phosphodieterase isoforms in cAMP compartmentation following $\beta 2$-adrenergic stimulation of ICa, $\mathrm{L}$ in frog ventricular myocytes. J Physiol 551:239-252. doi: 10.1113/jphysiol.2003.045211

24. Klarenbeek JB, Goedhart J, Hink MA, Gadella TWJ, Jalink K (2011) A mTurquoise-based CAMP sensor for both FLIM and ratiometric read-out has improved dynamic range. PLoS One 6:2-7. doi:

10.1371/journal.pone.0019170

25. Koller L, Kleber ME, Brandenburg VM, Goliasch G, Richter B, Sulzgruber P, Scharnagl H, Silbernagel G, Grammer TB, Delgado G, Tomaschitz A, Pilz S, Berger R, Mörtl D, Hülsmann M, Pacher R, März W, Niessner A (2015) Fibroblast Growth Factor 23 Is an Independent 
and Specific Predictor of Mortality in Patients With Heart Failure and Reduced Ejection Fraction. Circ Hear Fail 8:1059-1067. doi:

10.1161/CIRCHEARTFAILURE.115.002341

26. Kuro-o M (2019) The Klotho proteins in health and disease. Nat Rev Nephrol 15. doi: 10.1038/s41581-018-0078-3

27. Leineweber K, Böhm M, Heusch G (2006) Cyclic Adenosine Monophosphate in Acute Myocardial Infarction With Heart Failure Slayer or Savior? Circulation 114:365-367. doi:

10.1161/CIRCULATIONAHA.106.642132

28. Leroy J, Richter W, Mika D, Castro LR V, Abi-gerges A, Xie M, Scheitrum C, Lefebvre F, Schittl J, Mateo P, Westenbroek R, Catterall WA, Charpentier F, Conti M, Fischmeister R, Vandecasteele G (2011) Phosphodiesterase 4B in the cardiac L-type Ca $2+$ channel complex regulates $\mathrm{Ca} 2$ + current and protects against ventricular arrhythmias in mice. J Clin Invest 121:2651-2661. doi: 10.1172/JCI44747.association

29. Lutsey PL, Alonso A, Selvin E, Pankow JS, Michos ED, Agarwal SK, Loehr LR, Eckfeldt JH, Coresh J (2014) Fibroblast growth factor-23 and incident coronary heart disease, heart failure, and cardiovascular mortality: the atherosclerosis risk in communities study. J Am Hear Assoc 3:e000936. doi: 10.1161/JAHA.114.000936

30. Mehta R, Cai X, Lee J, Scialla JJ, Bansal N, Sondheimer JH, Chen J, Hamm LL, Ricardo AC, Navaneethan SD, Deo R, Rahman M, Feldman HI, Go AS, Isakova T, Wolf M, Appel LJ, He J, Kusek JW, Lash JP, Ojo A, Townsend RR (2016) Association of fibroblast growth factor 23 With atrial fibrillation in chronic kidney disease, from the Chronic Renal 
Insufficiency Cohort Study. JAMA Cardiol 1:548-556. doi:

10.1001/jamacardio.2016.1445

31. Mika $D$, Bobin $P$, Pomérance $M$, Lechêne $P$, Westenbroek RE, Catterall WA, Vandecasteele G, Leroy J, Fischmeister R (2013) Differential regulation of cardiac excitation-contraction coupling by cAMP phosphodiesterase subtypes. Cardiovasc Res 100:336-346. doi: $10.1093 /$ cvr/cvt193

32. Mizia-Stec K, Wieczorek J, Polak M, Wybraniec MT, WoźniakSkowerska I, Hoffmann A, Nowak S, Wikarek M, Wnuk-Wojnar A, Chudek J, Więcek A (2018) Lower soluble Klotho and higher fibroblast growth factor 23 serum levels are associated with episodes of atrial fibrillation. Cytokine 111:106-111. doi: 10.1016/j.cyto.2018.08.005

33. Molina CE, Leroy J, Richter W, Xie M, Scheitrum C, Lee IO, Maack C, Rucker-Martin C, Donzeau-Gouge P, Verde I, Llach A, Hove-Madsen L, Conti M, Vandecasteele G, Fischmeister R (2012) Cyclic adenosine monophosphate phosphodiesterase type 4 protects against atrial arrhythmias. J Am Coll Cardiol 59:2182-2190. doi:

10.1016/j.jacc.2012.01.060

34. Navarro-García JA, Delgado C, Fernández-Velasco M, Val-Blasco A, Rodríguez-Sánchez E, Aceves-Ripoll J, Gómez-Hurtado N, Bada-Bosch T, Mérida-Herrero E, Hernández E, Praga M, Salguero R, Solís J, Arribas F, Delgado JF, Bueno H, Kuro-O M, Ruilope LM, Ruiz-Hurtado G (2019) Fibroblast growth factor-23 promotes rhythm alterations and contractile dysfunction in adult ventricular cardiomyocytes. Nephrol Dial Transplant. doi: 10.1093/ndt/gfy392 
35. Nowak A, Bjorn F, Artunc F, Serra AL, Breidthardt T, Twerenbold R, Peter M, Mueller C (2014) Prognostic Value and Link to Atrial Fibrillation of Soluble Klotho and FGF23 in Hemodialysis Patients. PLoS One 9:111. doi: $10.1371 /$ journal.pone. 0100688

36. Oikawa M, Wu M, Lim S, Knight WE, Miller CL, Cai Y, Lu Y, Blaxall BC, Takeishi Y, Abe J ichi, Yan C (2013) Cyclic nucleotide phosphodiesterase $3 \mathrm{~A} 1$ protects the heart against ischemia-reperfusion injury. J Mol Cell Cardiol 64:11-19. doi: 10.1016/j.yjmcc.2013.08.003

37. Van Oort RJ, McCauley MD, Dixit SS, Pereira L, Yang Y, Respress JL, Wang Q, De Almeida AC, Skapura DG, Anderson ME, Bers DM, Wehrens XHT (2010) Ryanodine receptor phosphorylation by calcium/calmodulin-dependent protein kinase II promotes lifethreatening ventricular arrhythmias in mice with heart failure. Circulation 122:2669-2679. doi: 10.1161/CIRCULATIONAHA.110.982298

38. Pavik I, Jaeger P, Ebner L, Poster D, Krauer F, Kistler AD, Rentsch K, Andreisek G, Wagner CA, Devuyst O, Wuthrich RP, Schmid C, Serra AL (2012) Soluble klotho and autosomal dominant polycystic kidney disease. Clin J Am Soc Nephrol 7:248-257. doi:

10.2215/CJN.09020911

39. Plischke M, Neuhold S, Adlbrecht C, Bielesz B, Shayganfar S, Bieglmayer C, Szekeres T, Hörl WH, Strunk G, Vavken P, Pacher R, Hülsmann M (2012) Inorganic phosphate and FGF-23 predict outcome in stable systolic heart failure. Eur J Clin Invest 42:649-656. doi: 10.1111/j.1365-2362.2011.02631.x

40. Prié D, Forand A, Francoz C, Elie C, Cohen I, Courbebaisse M, Eladari 
D, Lebrec D, Durand F, Friedlander G (2013) Plasma Fibroblast Growth Factor 23 Concentration Is Increased and Predicts Mortality in Patients on the Liver-Transplant Waiting List. PLoS One 8:e66182. doi:

10.1371/journal.pone.0066182

41. Respress JL, Van Oort RJ, Li N, Rolim N, Dixit SS, Dealmeida A, Voigt N, Lawrence WS, Skapura DG, Skårdal K, Wisløff U, Wieland T, Ai X, Pogwizd SM, Dobrev D, Wehrens XHT (2012) Role of RyR2 phosphorylation at S2814 during heart failure progression. Circ Res 110:1474-1483. doi: 10.1161/CIRCRESAHA.112.268094

42. Rochais F, Abi-Gerges A, Horner K, Lefebvre F, Cooper DMF, Conti M, Fischmeister R, Vandecasteele G (2006) A specific pattern of phosphodiesterases controls the cAMP signals generated by different Gs-coupled receptors in adult rat ventricular myocytes. Circ Res 98:1081-1088. doi: 10.1161/01.RES.0000218493.09370.8e

43. Rochais F, Vandecasteele G, Lefebvre F, Lugnier C, Lum H, Mazet JL, Cooper DMF, Fischmeister R (2004) Negative feedback exerted by cAMP-dependent protein kinase and cAMP phosphodiesterase on subsarcolemmal cAMP signals in intact cardiac myocytes: An in vivo study using adenovirus-mediated expression of CNG channels. J Biol Chem 279:52095-52105. doi: 10.1074/jbc.M405697200

44. Sanja B, Faiyaz A, Weixing S, Jie L, Samy M, Nazari P, Junhui S, Steven H, Wook CY, Matthew M, Elizabeth M, Vincent M, H. BP (2013) Phosphodiesterase Type 3A Regulates Basal Myocardial Contractility Through Interacting With Sarcoplasmic Reticulum Calcium ATPase Type 2a Signaling Complexes in Mouse Heart. Circ Res 112:289-297. 
doi: 10.1161/CIRCRESAHA.111.300003

45. Sari F, Inci A, Dolu S, Ellidag HY, Cetinkaya R, Ersoy FF (2017) High serum soluble $\alpha$-Klotho levels in patients with autosomal dominant polycystic kidney disease. J Investig Med 65:358-362. doi: 10.1136/jim2016-000193

46. Segawa H, Yamanaka S, Ohno Y, Onitsuka A, Shiozawa K, Aranami F, Furutani J, Tomoe Y, Ito M, Kuwahata M, Imura A, Nabeshima Y, Miyamoto KI (2007) Correlation between hyperphosphatemia and type II Na-Pi cotransporter activity in klotho mice. Am J Physiol - Ren Physiol 292:769-779. doi: 10.1152/ajprenal.00248.2006

47. Seiler S, Rogacev KS, Roth HJ, Shafein P, Emrich I, Neuhaus S, Floege J, Fliser D, Heine GH (2014) Associations of FGF-23 and sklotho with cardiovascular outcomes among patients with CKD stages 2-4. Clin J Am Soc Nephrol 9:1049-1058. doi: 10.2215/CJN.07870713

48. Shalhoub V, Shatzen EM, Ward SC, Davis J, Stevens J, Bi V, Renshaw L, Hawkins N, Wang W, Chen C, Tsai M-M, Cattley RC, Wronski TJ, Xia X, Li X, Henley C, Eschenberg M, Richards WG (2012) FGF23 neutralization improves chronic kidney disease-associated hyperparathyroidism yet increases mortality. J Clin Invest 122:25432553. doi: $10.1172 / j c i 61405$

49. Shannon TR, Ginsburg KS, Bers DM (2002) Quantitative assessment of the SR Ca2+ leak-load relationship. Circ Res 91:594-600

50. Souberbielle JC, Prié D, Piketty ML, Rothenbuhler A, Delanaye P, Chanson P, Cavalier E (2017) Evaluation of a New Fully Automated Assay for Plasma Intact FGF23. Calcif Tissue Int 101:510-518. doi: 
10.1007/s00223-017-0307-y

51. Takeshita K, Fujimori T, Kurotaki Y, Honjo H, Yasui K, Lee J, Kamiya K, Kitaichi K, Ito M, Kondo T, lino S, Inden Y, Takeshita K, Fujimori T, Kurotaki Y, Honjo H (2004) Sinoatrial Node Dysfunction and Early Unexpected Death of. doi: 10.1161/01.CIR.0000124224.48962.32

52. Tanaka S, Fujita S, Kizawa S, Morita H, Ishizaka N (2016) Association between FGF23, $\alpha-K l o t h o$, and Cardiac Abnormalities among Patients with Various Chronic Kidney Disease Stages. PLoS One 11:e0156860. doi: 10.1371/journal.pone.0156860

53. Udell JA, Morrow DA, Jarolim P, Sloan S, Hoffman EB, O’Donnell TF, Vora AN, Omland T, Solomon SD, Pfeffer MA, Braunwald E, Sabatine MS (2014) Fibroblast growth factor-23, cardiovascular prognosis, and benefit of angiotensin-converting enzyme inhibition in stable ischemic heart disease. J Am Coll Cardiol 63:2421-2428. doi:

10.1016/j.jacc.2014.03.026

54. Verde I, Vandecasteele G, Lezoualc'h F, Fischmeister R (1999) Characterization of the cyclic nucleotide phosphodiesterase subtypes involved in the regulation of the L-type $\mathrm{Ca} 2+$ current in rat ventricular myocytes. Br J Pharmacol 127:65-74. doi: 10.1038/sj.bjp.0702506

55. Webster AC, Nagler E V, Morton RL, Masson P (2016) Chronic Kidney Disease. Lancet 6736:1-15. doi: 10.1016/S0140-6736(16)32064-5

56. Wright JD, An SW, Xie J, Lim C, Huang CL (2019) Soluble klotho regulates TRPC6 calcium signaling via lipid rafts, independent of the FGFR-FGF23 pathway. FASEB J 33:9182-9193. doi:

10.1096/fj.201900321R 
57. Xie J, Cha SK, An SW, Kuro-O M, Birnbaumer L, Huang CL (2012)

Cardioprotection by Klotho through downregulation of TRPC6 channels in the mouse heart. Nat Commun 3:1211-1238. doi:

$10.1038 /$ ncomms 2240

58. Yang H, Luo H, Tang X, Zeng X, Yu Y, Ma L, Fu P (2016) Prognostic value of FGF23 among patients with end-stage renal disease: a systematic review and meta-analysis. Biomark Med 10:547-556. doi: 10.2217/bmm.16.11

\begin{tabular}{|l|c|c|c|c|c|}
\hline Isoproterenol & Control & FGF23 & sKlotho & $\begin{array}{c}\text { FGF23 + } \\
\text { sKlotho }\end{array}$ & p-value \\
\hline $1 \mathrm{nM}$ & 0 & $45.8 \%$ & 0 & $6 \%$ & 0.000075 \\
\hline $10 \mathrm{nM}$ & $62.5 \%$ & $95 \%$ & $41.1 \%$ & $56.6 \%$ & 0.002723 \\
\hline
\end{tabular}

Table1. Percent of cells with spontaneous $\mathrm{Ca}^{2+}$ waves in the presence of ISO (1 or $10 \mathrm{nM})$ after treatment with vehicle (CON), FGF23 (6 ng/ml), sKlotho $(0.95 \mathrm{ng} / \mathrm{ml})$ or FGF23+sKlotho. Statistical significance was determined by Fisher's exact test to compare occurrence of events. ( $N=3$ rats, $n=16-20$ cells per group). 


\section{Figure legends:}

Fig. 1. FGF23 potentiates the effect of submaximal $\beta-A R$ stimulation on SR $\mathrm{Ca}^{2+}$ leak while kept normal SR $\mathrm{Ca}^{2+}$ load. A: Representative traces of $\mathrm{SR} \mathrm{Ca}^{2+}$ leak and load measurements in Fura-2 loaded ARVMs treated with control solution or FGF23 $(6 \mathrm{ng} / \mathrm{ml})$ for $24 \mathrm{~h}$ upon $\beta$-AR stimulation by ISO $(10 \mathrm{nM})$. Tetracaine (1 mM) was used to measure SR $\mathrm{Ca}^{2+}$ leak and caffeine $(10 \mathrm{mM})$ was used to measure SR $\mathrm{Ca}^{2+}$ load. B: Mean amplitude ( $\pm \mathrm{SEM}$ ) of $\mathrm{SR} \mathrm{Ca}^{2+}$ leak. C: Mean amplitude ( \pm SEM) of SR $\mathrm{Ca}^{2+}$ load. D: Representative traces of spontaneous $\mathrm{Ca}^{2+}$ waves in Fura-2 loaded ARVMs upon $\beta$-AR stimulation with ISO (10 nM). E: Average occurence of spontaneous $\mathrm{Ca}^{2+}$ waves $( \pm \mathrm{SEM})$ recorded during a 20s pacing pause. Statistical significance was determined by Student's t test to compare the 2 groups, ${ }^{*} \mathrm{p}<0.05,{ }^{* * *} \mathrm{p}<0.001$ vs. control $(\mathrm{N}=4$ rats, $n=12$ cells per group).

Fig. 2. Phosphorylation of $\mathrm{Ca}^{2+}$ handling $\mathrm{SR}$ proteins is increased in FGF23treated cardiomyocytes and is prevented by sKlotho. Lysates prepared from ARVMs treated with vehicle (Ctrl), FGF23 (6 $\mathrm{ng} / \mathrm{ml})$ or in combination of FGF23 $(6 \mathrm{ng} / \mathrm{ml})$ with sKlotho $(0.95 \mathrm{ng} / \mathrm{ml})$ were analyzed by immunoblot with the indicated specific antibodies. Protein phosphorylation was normalized to the respective total protein. Immunoblots are shown in A and B. C: quantification of immunoblots shown in A upper panel, D: quantification of immunoblots shown in B upper panel. PLB: phospholamban, RyR: Ryanodine Receptor. 
Data are presented as a fold change from the control (Ctrl) levels $( \pm S E M)$, statistical significance was determined by Student's t test, ${ }^{*} p<0.05,{ }^{*} p=0.001$, ${ }^{* *} \mathrm{p}=0.0002$ vs. control ( $\mathrm{N}=4$ rats per group).

Fig. 3. Intracellular cAMP concentration and PDE isoform expression in ARVMs treated with vehicle, FGF23, sKlotho and cyclosporine A. A,C: Normalized average time course of [CAMP] in response to a $15 \mathrm{~s}$ application of ISO (30 nM) in ventricular myocytes infected with an adenovirus expressing the FRET (Förster Resonance Energy Transfer)-based cAMP probe Epac-S ${ }^{\mathrm{H} 187}$. Maximal [cAMP]i was significantly higher in FGF23-treated $(6 \mathrm{ng} / \mathrm{ml})$ cells than in control conditions (Anova, ${ }^{* * *} p<0.0001$, Dunnet's t-test ${ }^{* * *} \mathrm{p}=0.0006$ FGF23 vs. control). sKlotho $(0.95 \mathrm{ng} / \mathrm{ml})$ and cyclosporine $\mathrm{A}(\mathrm{CspA}, 1 \mu \mathrm{M})$ prevented the effect of FGF23 on cAMP accumulation ( $N=3$ rats, $n=15-18$ cells per group). B: Decay kinetics ( $t_{1 / 20 f f}$ of cAMP response shown in $A$ and $C$ (Anova, ${ }^{* * *} p<0.0001$, Dunnetts's $t$ test, ${ }^{* * *} p<0.0001$ vs. control). sKlotho $(0.95 \mathrm{ng} / \mathrm{ml})$ and CspA ( $1 \mu \mathrm{M}$ prevented the effect of FGF23 on decay kinetics of cAMP. All data are presented as mean ( $\pm S E M, N=3$ rats, $n=15-18$ cells per group) $D$ : Representatiove immunoblot showing expression of PDE3A, 3B, 4A and 4B in ARVMs in control condition (Ctrl) or after treatment with FGF23 $(6 \mathrm{ng} / \mathrm{ml})$ for 24h. E: Quantification of immunoblot shown in D, FGF23-treated ARVMs show a lower expression of PDE4B isoform expression, data are presented as a fold change from the control (Ctrl) levels $( \pm S E M)$, Student's $t$ test, ${ }^{* *} p<0.01 \mathrm{vs}$. control ( $\mathrm{N}=5$ rats per group). F: RT-PCR showing the mRNA expression of PDE3A, 3B, 4A and 4B in ARVMs treated with control solution or FGF23 
(6ng/ml). FGF23-treated ARVMs show a lower PDE4B mRNA level. All data are shown as mean $\left( \pm\right.$ SEM), Student's $t$ test, ${ }^{* *} p<0.001 v$ s. control $(N=4$ rats per group).

Fig. 4. FGF2 did not modify the expression of PDE4B, sKlotho and cyclosporine A completely prevent FGF23-induced inhibition of PDE4B. Lysates prepared from ARVMs treated with control solution, FGF2 $(6 \mathrm{ng} / \mathrm{ml})$ or in combination of FGF23 $(6 \mathrm{ng} / \mathrm{ml})$ with sKlotho $(0.95 \mathrm{ng} / \mathrm{ml})$ or CspA $(1 \mu \mathrm{M})$ were analyzed by immunoblot with the indicated specific antibodies. Protein expression was normalized to calsequestrin (CSQ). Immunoblots are shown in A, B and C left panels and the quantifications in $\mathbf{A}$ right panels andD. Data are presented as a fold change from the control (Ctrl) levels ( \pm SEM), statistical significance was determined by Anova and Tukey Kramer's test, ${ }^{* * *} \mathrm{p}<0.001$ vs. control $(\mathrm{N}=2-4$ rats per group).

Fig. 5. Acute stimulation of ARVMs with FGF23 activates phosphorylated PLCY and FGF23 treatment within 24h decreases phosphorylation level of Akt. Lysates prepared from ARVMs treated with control solution, phenylephrine (50 $\mu \mathrm{M})$ during $10 \mathrm{~min}(\mathrm{~A})$, FGF23 $(6 \mathrm{ng} / \mathrm{mL})$ during $15 \mathrm{~min}(\mathrm{~A}, \mathrm{C})$ or with FGF23 $(6 \mathrm{ng} / \mathrm{ml})$ during $24 \mathrm{~h}(\mathrm{~B}, \mathrm{D})$ were analyzed by immunoblot with the indicating specific antibodies. Immunoblots are shown in A,B,C,D left panels and their quantification in $A, B, C, D$ right panels. Data are presented as a fold change from the control (Ctrl) levels $( \pm S E M)$. A: Statistical significance was determined by One-way ANOVA followed by Tukey's multiple comparison test, ${ }^{*} p<0.05$, 
${ }^{* * *} \mathrm{p}<0.001$ vs. control ( $\mathrm{N}=3-4$ rats per group); B: Statistical significance was determined by Student's $\mathrm{T}$ test, ${ }^{* *} \mathrm{p}<0.01 \mathrm{vs}$. control ( $\mathrm{N}=4$ rats per group), $\mathrm{C}$ : Statistical significance was determined by One-way ANOVA followed by Tukey's multiple comparison test, ${ }^{* *} p<0.01,{ }^{* *} p<0.001$ vs. control, $\$ \$ p<0.01$ vs. Phe( $\mathrm{N}=3-4$ rats per group); $\mathrm{D}$ : No difference was observed after treatment with FGF23 compared to control group ( $\mathrm{N}=4$ rats per group).

Fig 6. FGF23 and sKlotho did not modify the phosphorylation level of ERK. Lysates prepared from ARVMs treated with control solution, phenylephrine $(50 \mu \mathrm{M})$ during $10 \mathrm{~min}(\mathrm{~A})$, FGF23 $(6 \mathrm{ng} / \mathrm{mL})$ during $15 \mathrm{~min}(\mathrm{~A})$ or with FGF23 $(6 \mathrm{ng} / \mathrm{ml})$ during $24 \mathrm{~h}(\mathrm{~B}, \mathrm{C})$ were analyzed by immunoblot with the indicating specific antibodies. Immunoblots are shown in A,B,C left panels and their quantification in $A, B, C$ right panels. Data are presented as a fold change from the control (Ctrl) levels ( \pm SEM). A: Statistical significance was determined by One-way ANOVA followed by Tukey's multiple comparison test, ${ }^{*} p<0.05$ vs. control and FGF23 group ( $\mathrm{N}=3-4$ rats per group). B: No difference was observed after treatment with FGF23 compared to control group ( $N=4$ rats per group). C: The phosphorylation of ERK was not different between the groups ( $\mathrm{N}=2$ rats per group).

Fig. 7. Ventricular myocytes treated with FGF23 showed increased $\beta$ adrenergic response of L-type $\mathrm{Ca}^{2+}$ current and is prevented by sKlotho, cyclosporine A or FGFR antagonist. Normalized average time course of $\mathrm{ICa}_{\mathrm{C}} \mathrm{L}$ amplitude after ISO pulse stimulation (30 nM) in control and FGF23 treated cells $(\mathbf{A}, \mathbf{B}, \mathbf{E})$ and in the presence of cyclosporine $A(\mathbf{A})$, FGFR antagonist (B) 
or sKlotho (E). Each square represents the amplitude of $\mathrm{I}_{\mathrm{C} a, \mathrm{~L}}$ recorded every $8 \mathrm{~s}$ during a depolarization from -50 to $0 \mathrm{mV}$. C, D, F: Averaged current densities recorded under basal conditions. All data are presented as mean ( \pm SEM), statistical significance was determined by Anova and Tukey Kramer's test, ${ }^{* * *} \mathrm{p}<0.0001$ vs. control ( $\mathrm{N}=4$ rats, $\mathrm{n}=16-52$ cells per group).

Fig. 8. Effects of sKlotho on PDE3 expression and the phosphorylation of $\mathrm{Ca}^{2+}$ handling SR proteins. Lysates prepared from ARVMs treated with control solution, sKlotho $(0.95 \mathrm{ng} / \mathrm{ml})$ or with a combination of sKlotho $(0.95 \mathrm{ng} / \mathrm{ml})$ and FGF23 $(6 \mathrm{ng} / \mathrm{ml})$ were analyzed by immunoblot with the indicating specific antibodies. Protein expression was normalized to calsequestrin (CSQ). Protein phosphorylation was normalized to the respective total protein. Immunoblots are shown in $\mathbf{A}, \mathbf{B}$ and $\mathbf{C}$ left panels and the quantifications in $\mathbf{A}, \mathbf{B}$ and $\mathbf{C}$ right panels. A: sKlotho increases PDE3A and PDE3B expression, B: FGF23 in combination with sKlotho did not modify the expression of PDE isoforms, C: sKlotho decreases RyR and PLB phosphorylations. Data are presented as a fold change from the control (Ctrl) levels ( \pm SEM), statistical significance was determined by Student's t test, ${ }^{* *} p<0.01,{ }^{* * *} p<0.001$ vs. control $(N=4$ rats per group).

Fig. 9. Subtotal nephrectomy induces cardiac hypertrophy and modifies PDE4B expression. A: Changes in serum creatinine level measured in sham-operated (Sham) and subtotally-nephrectomized Nx mice, B: Heart weight over body 
weight was increased after Nx C: FGF23 serum level was increased in Nx animals, D: Nx surgery decreases PDE4B mRNA level measured by quantitative RT-PCR, E: PDE4B protein expression is decreased in Nx animals without any change in PDE3A, 3B and 4A expression level. Left panel shows immunoblot and right panel its quantification. Protein expression was normalized to calsequestrin (CSQ) Data are presented as a fold change from the control (Ctrl) levels ( \pm SEM). Statistical significance was determined by Student's $t$ test (Nephrectomy vs. Sham-operated), ${ }^{* *} \mathrm{p}<0.01,{ }^{* * *} \mathrm{p}<0.001 \mathrm{vs}$. sham-operated ( $\mathrm{N}=6-11$ mice per group). 


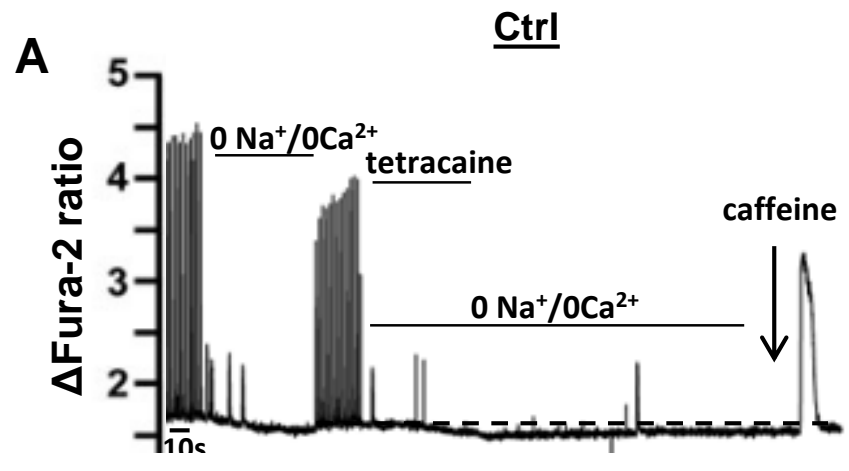

\section{FGF23}

B

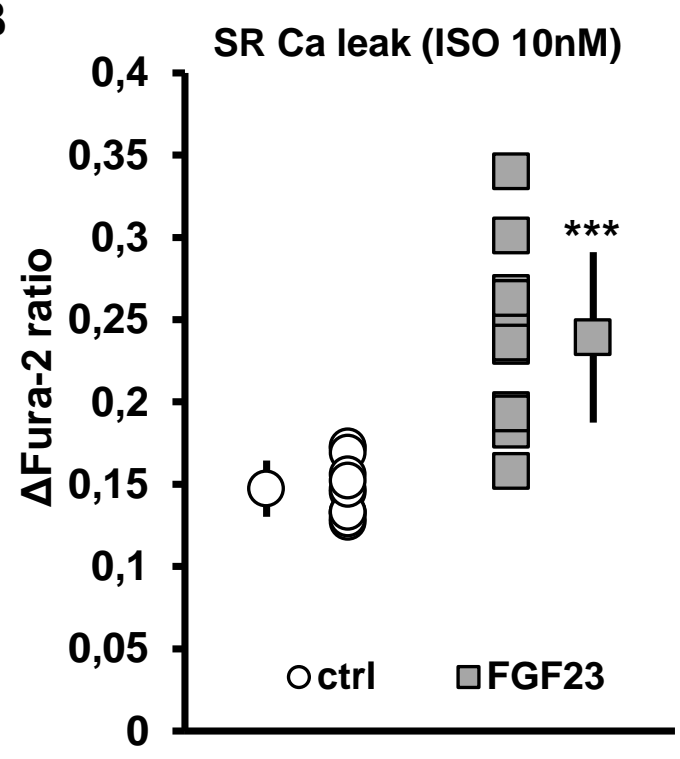

C
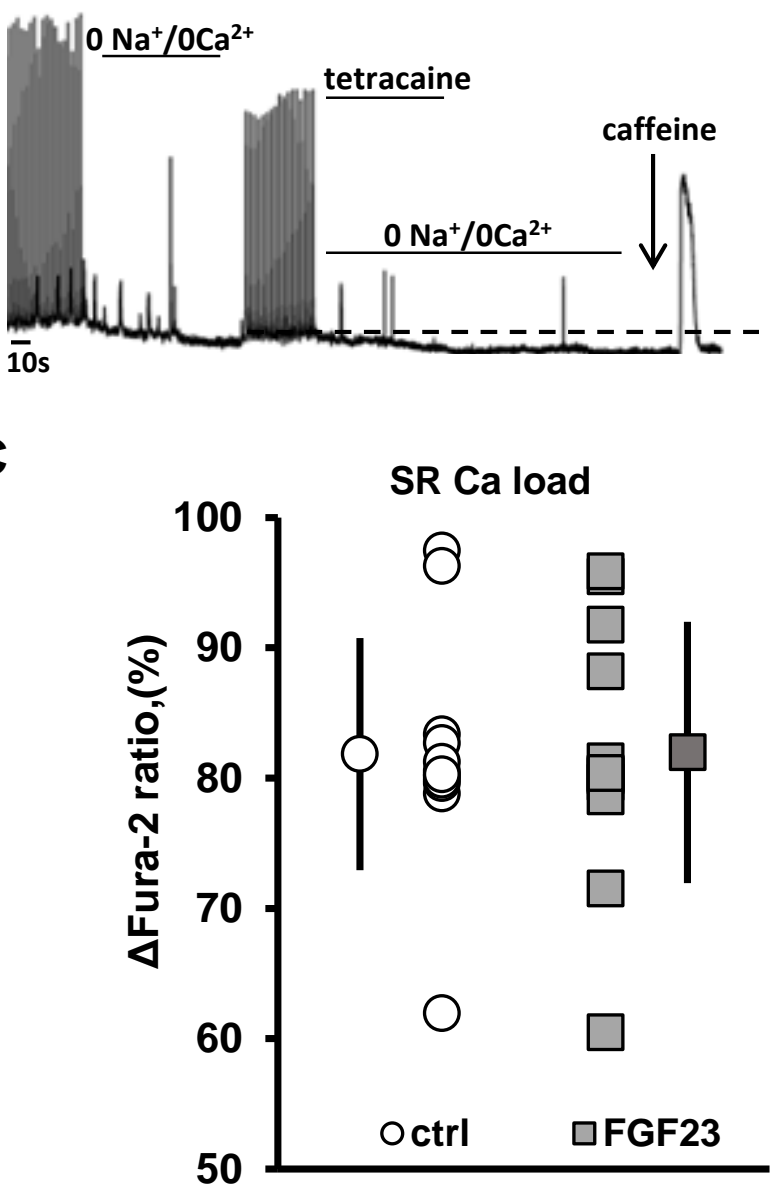

D
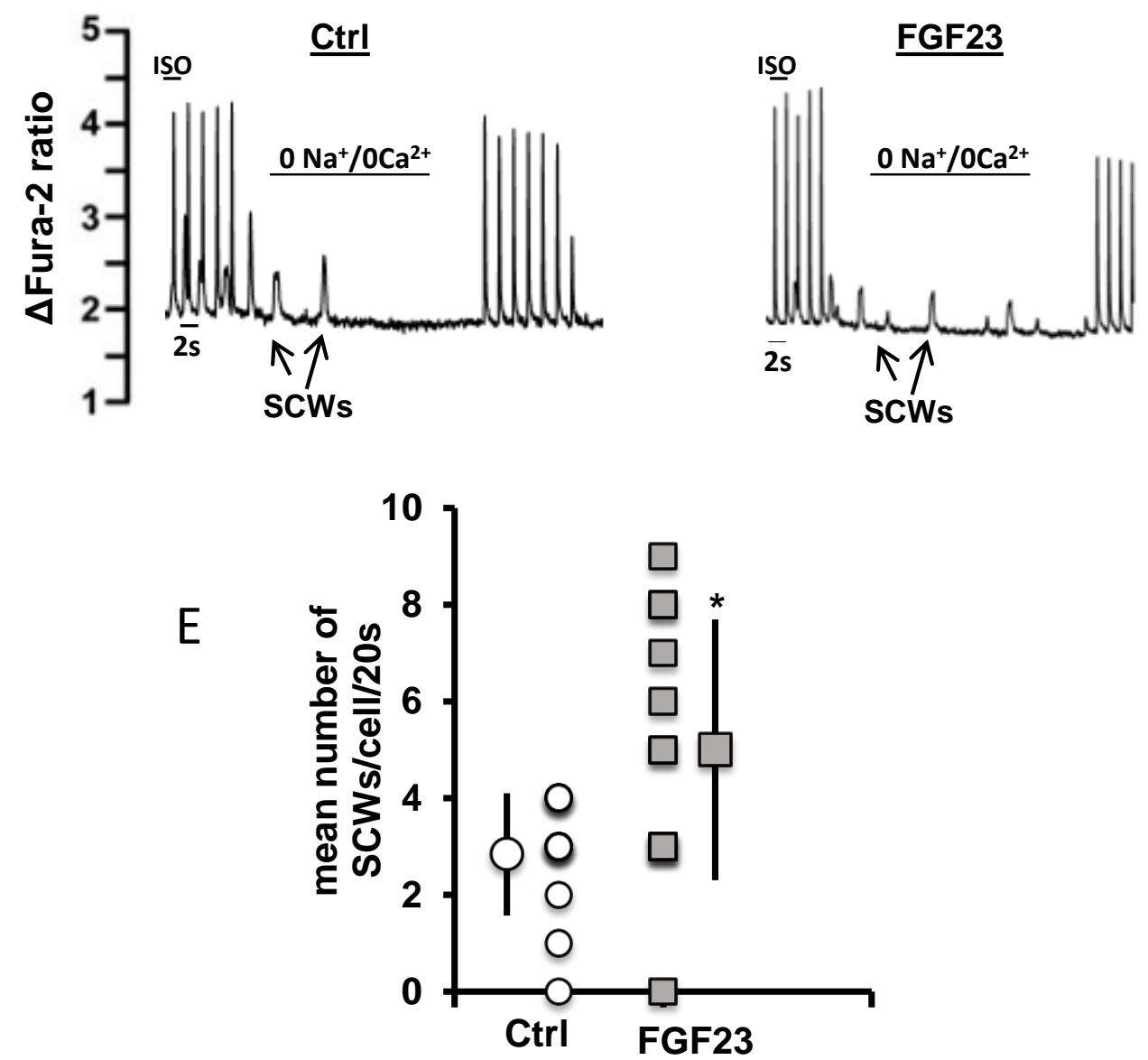

Figure 1 
A

B

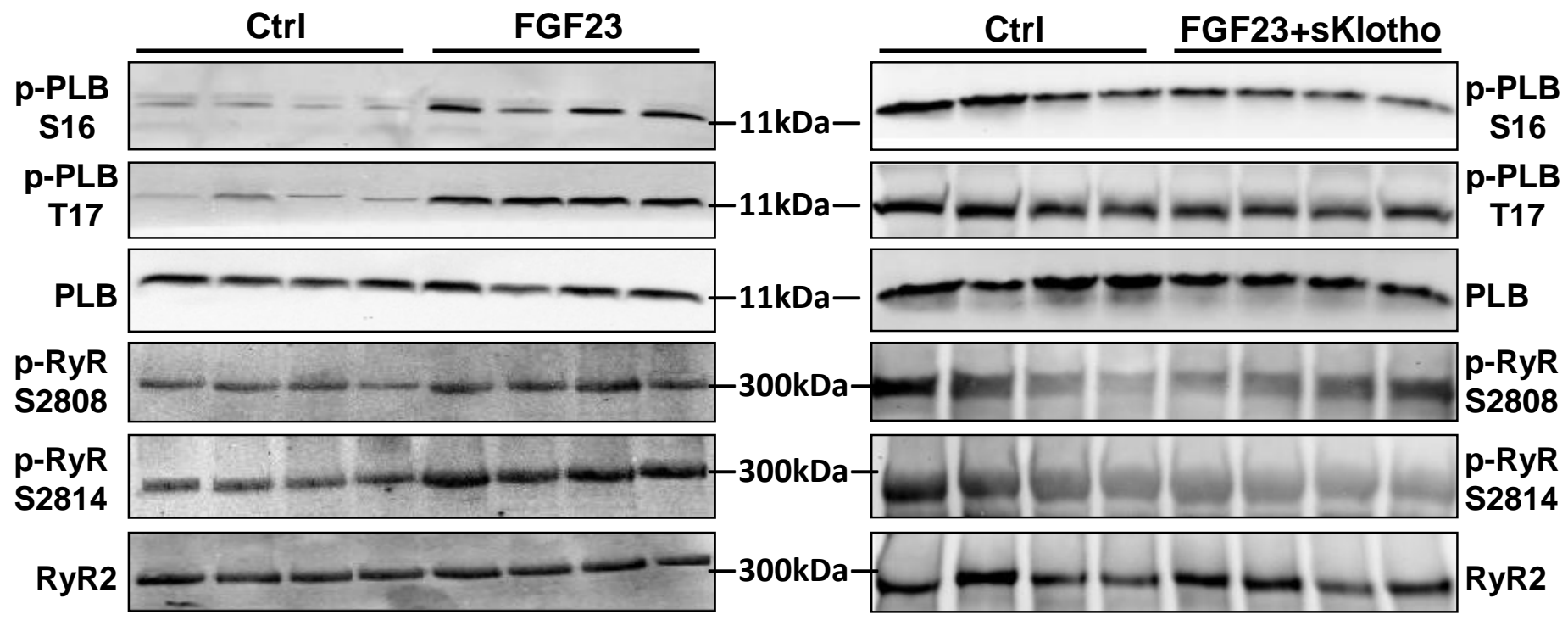

C

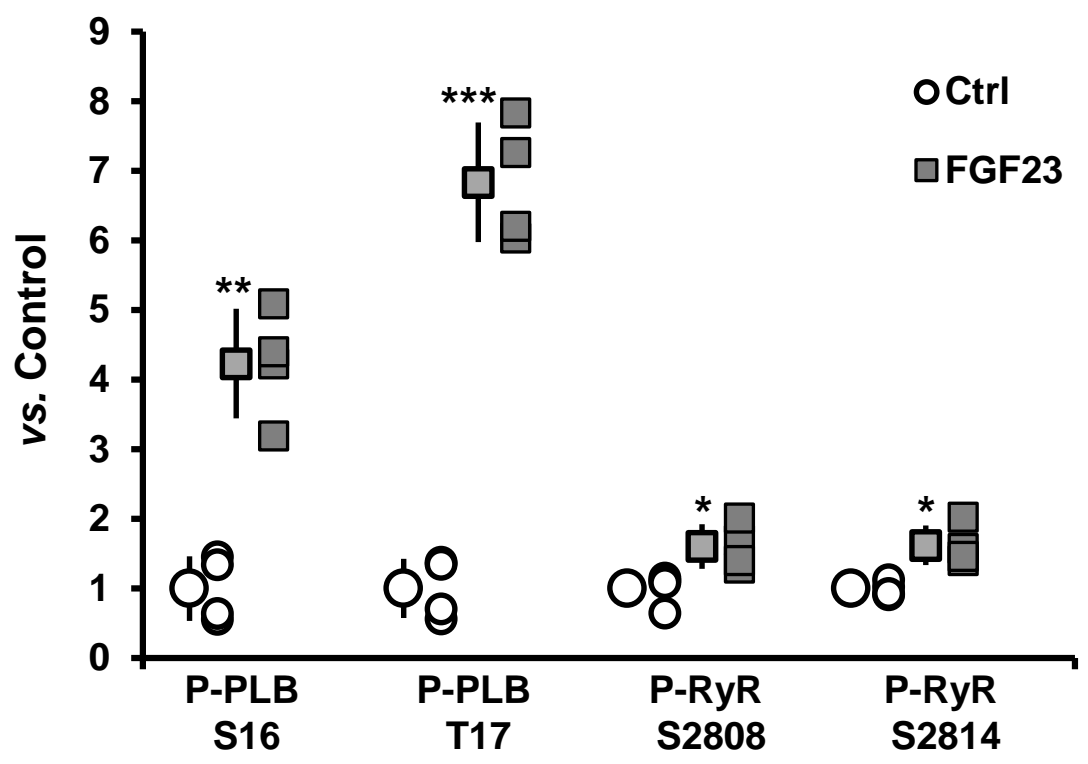

D

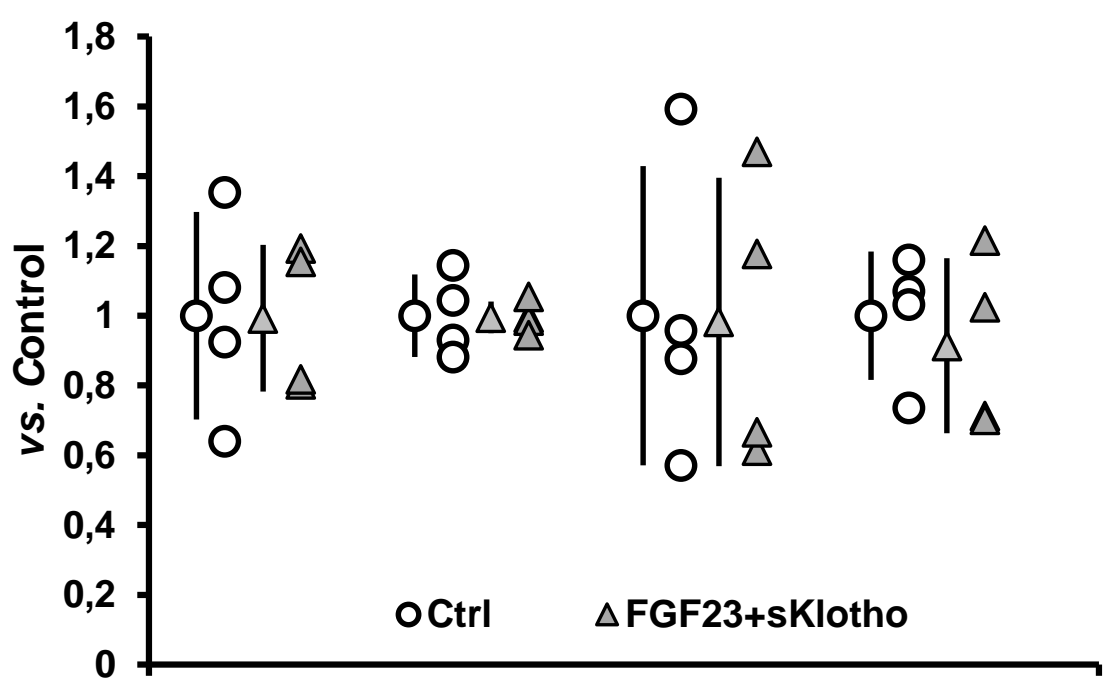


A

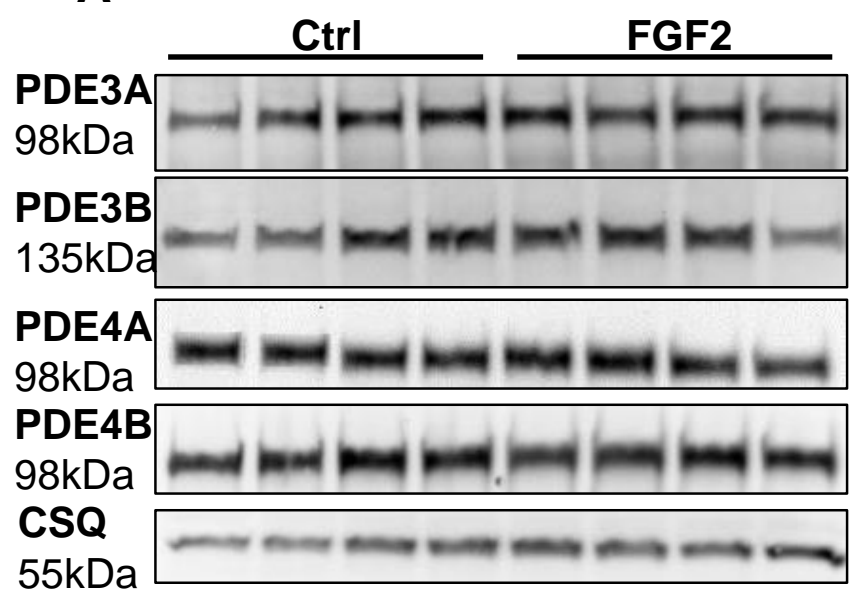

B
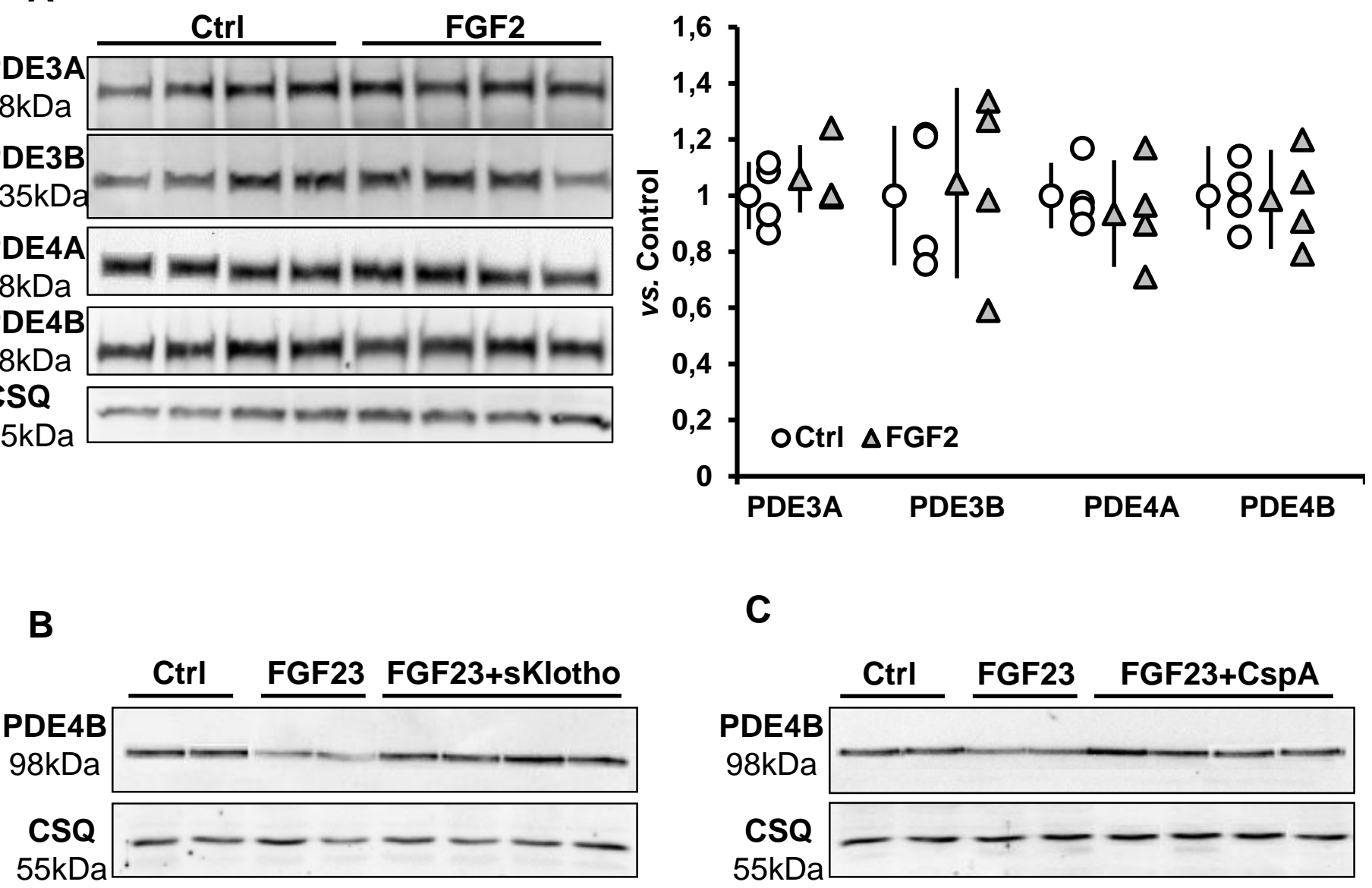

D

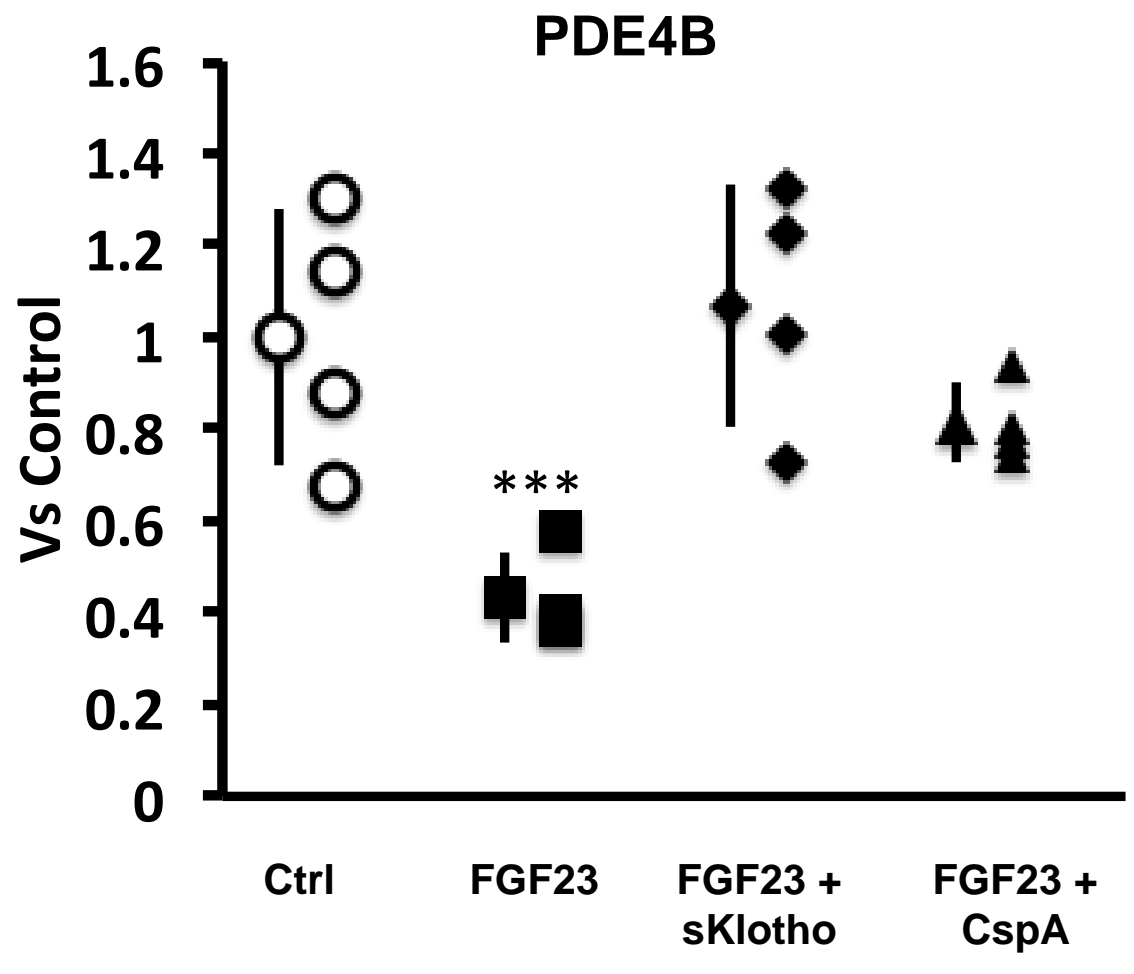


A

p-Akt S473 $60 \mathrm{kDa}$

p-Akt T308 $60 \mathrm{kDa}$

Total Akt $60 \mathrm{kDa}$

\section{Ctrl \\ Phe \\ FGF23}


A

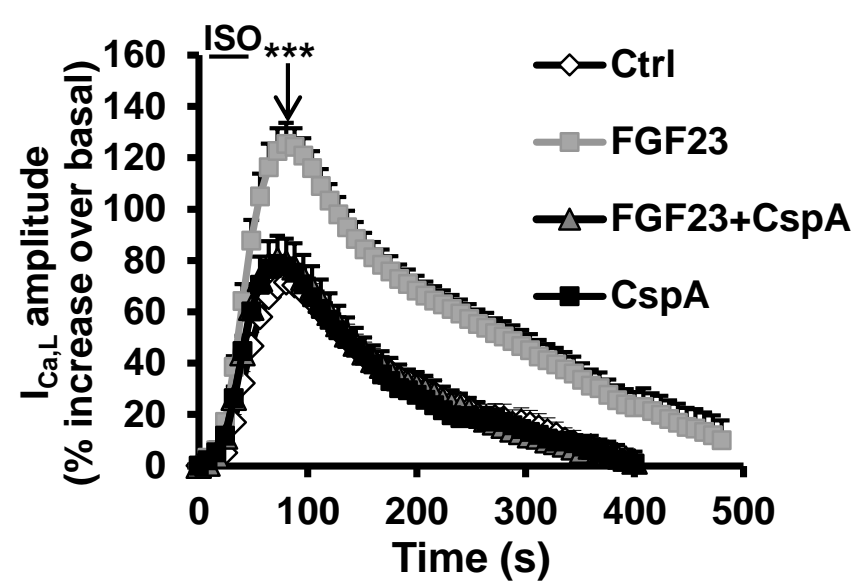

C

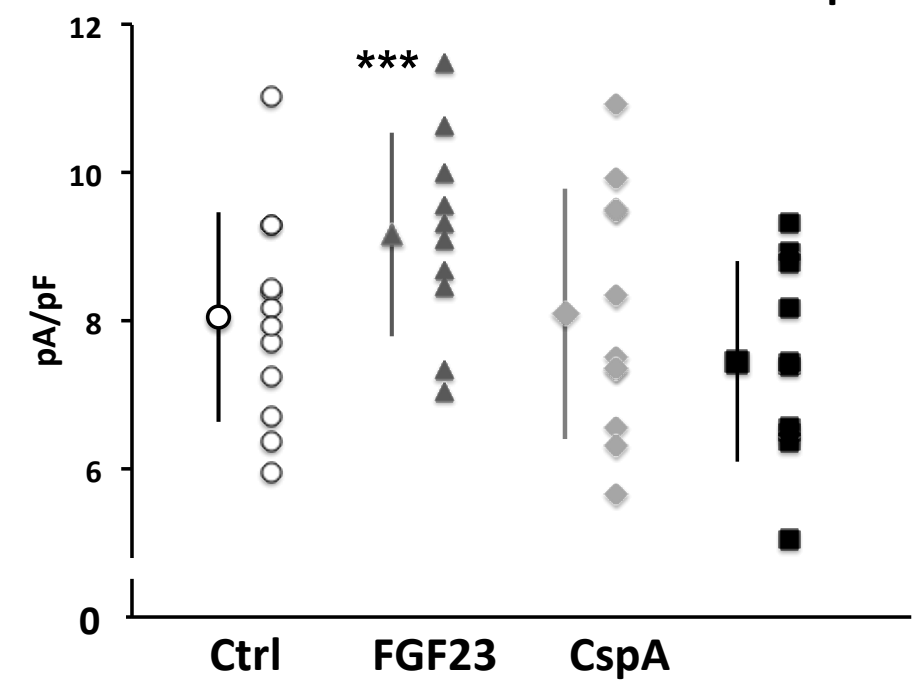

E

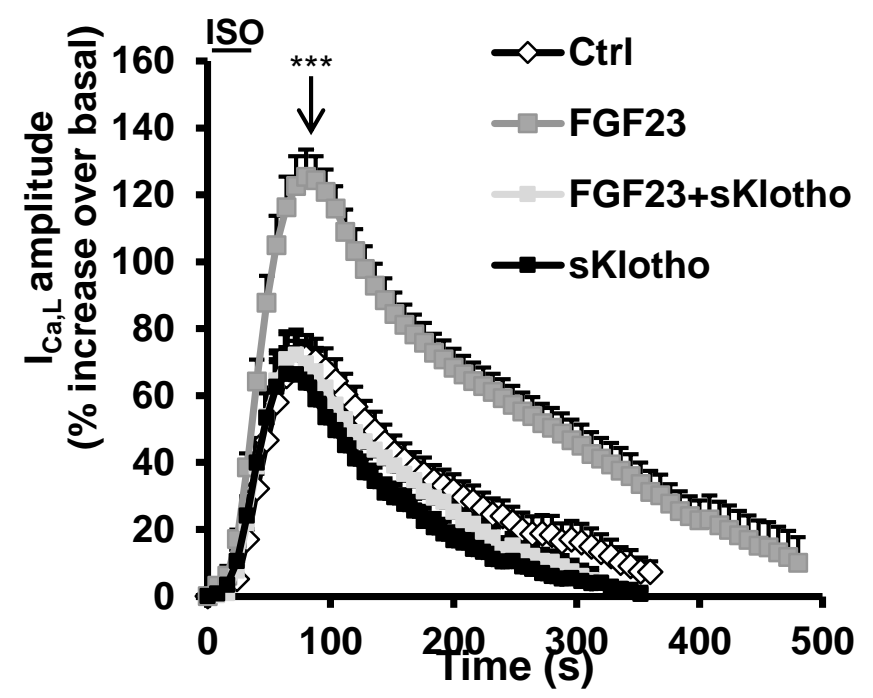

B

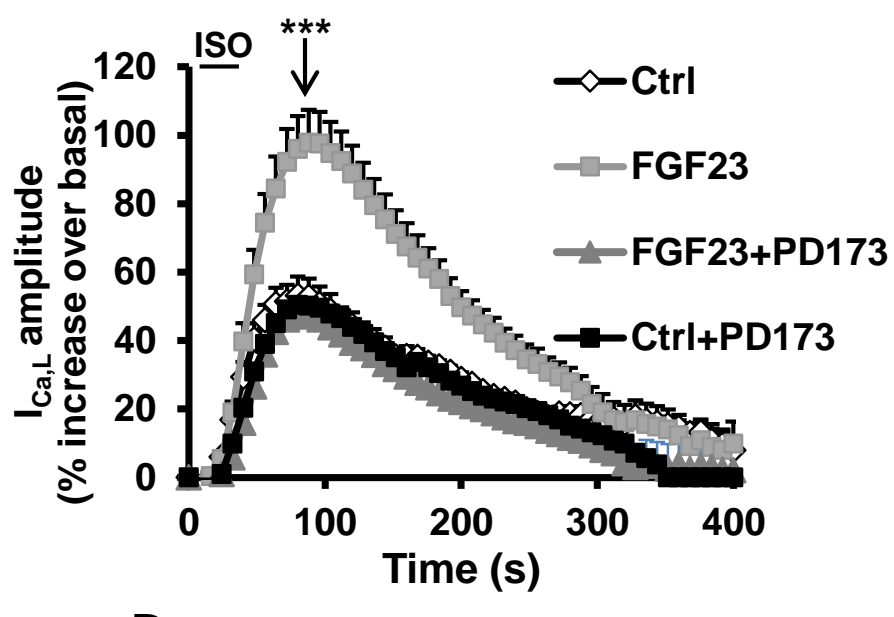

D

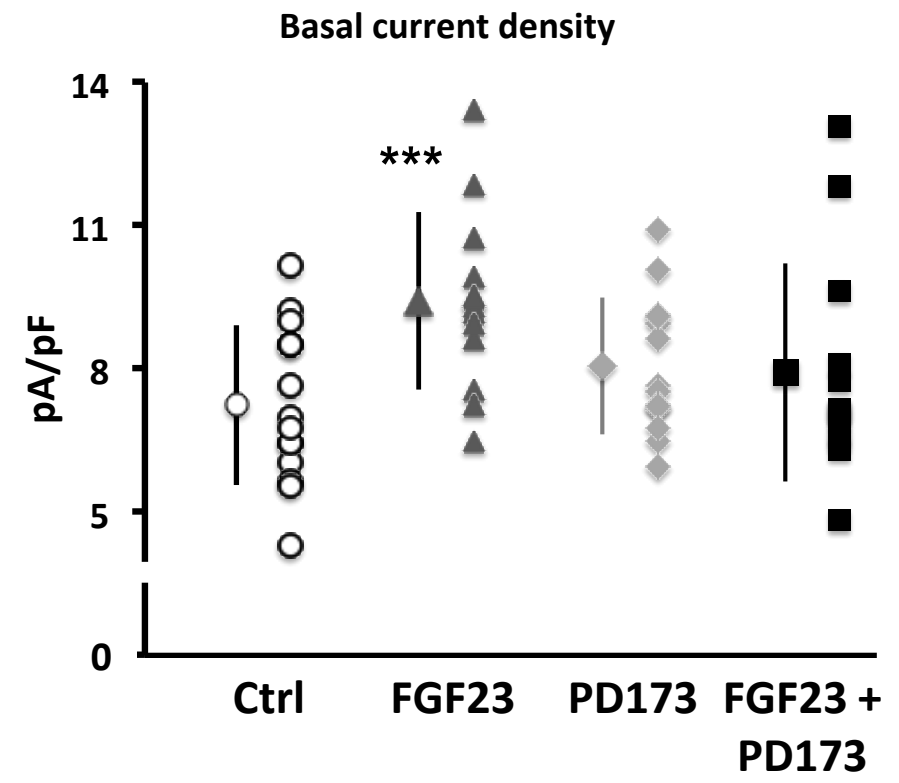

F

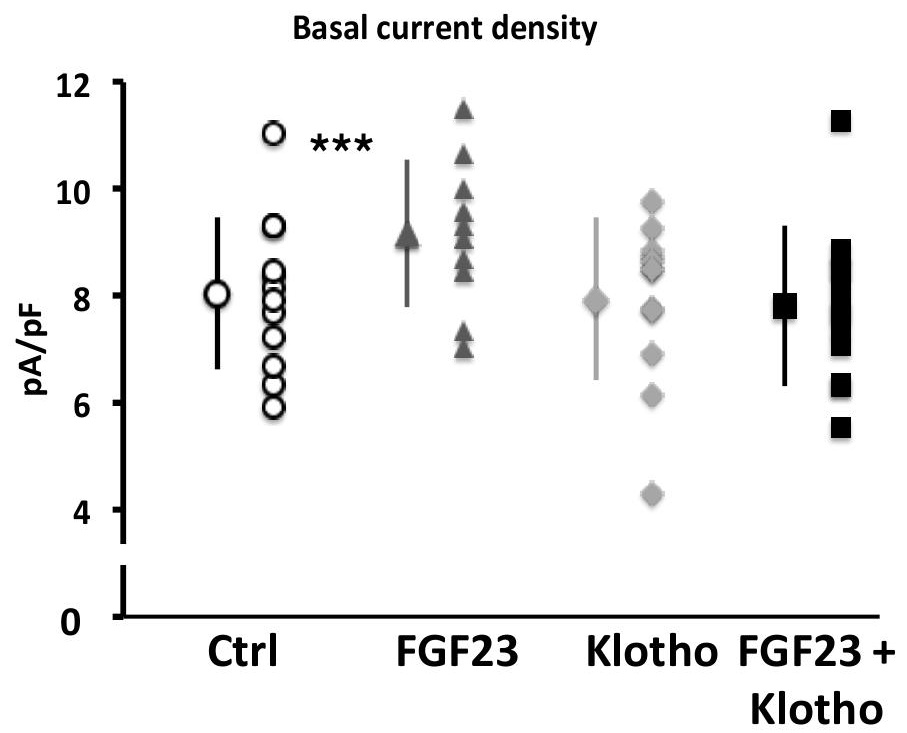



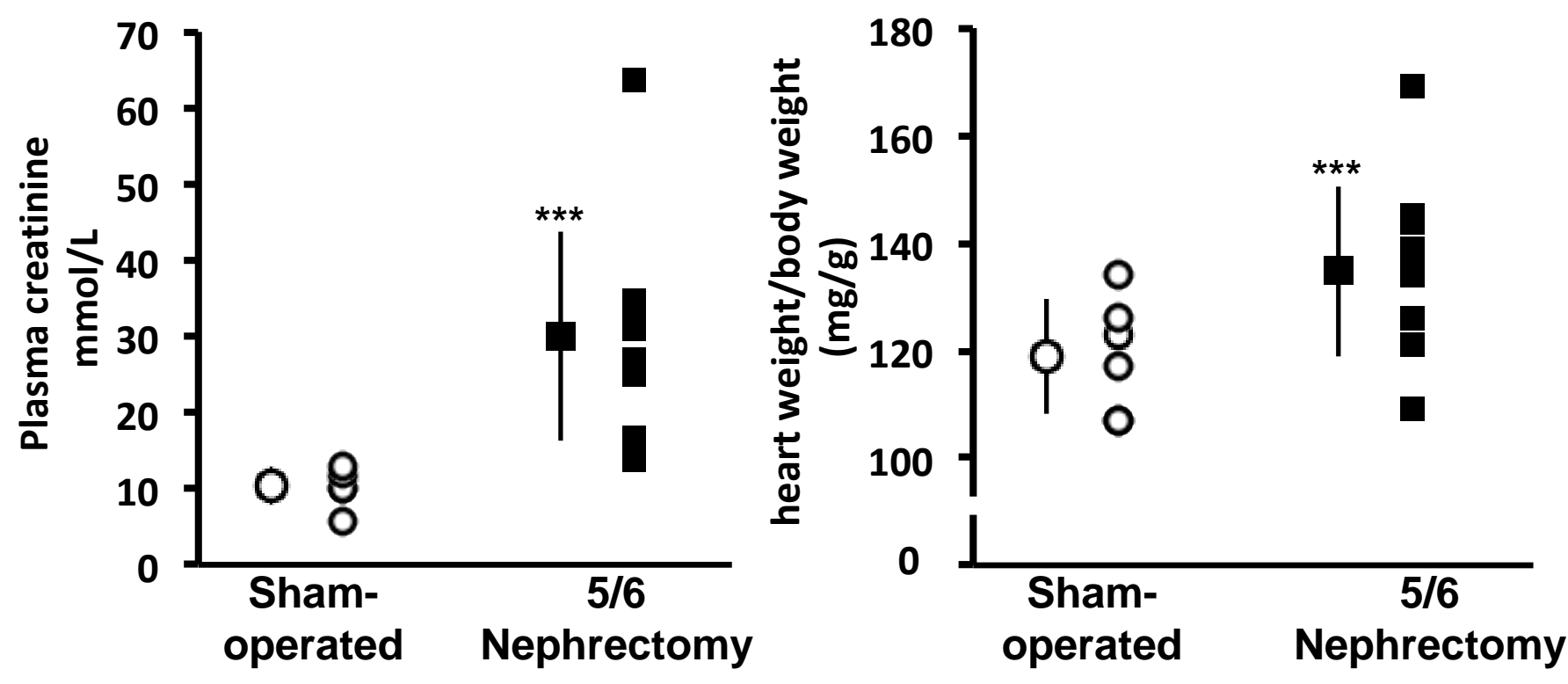

C
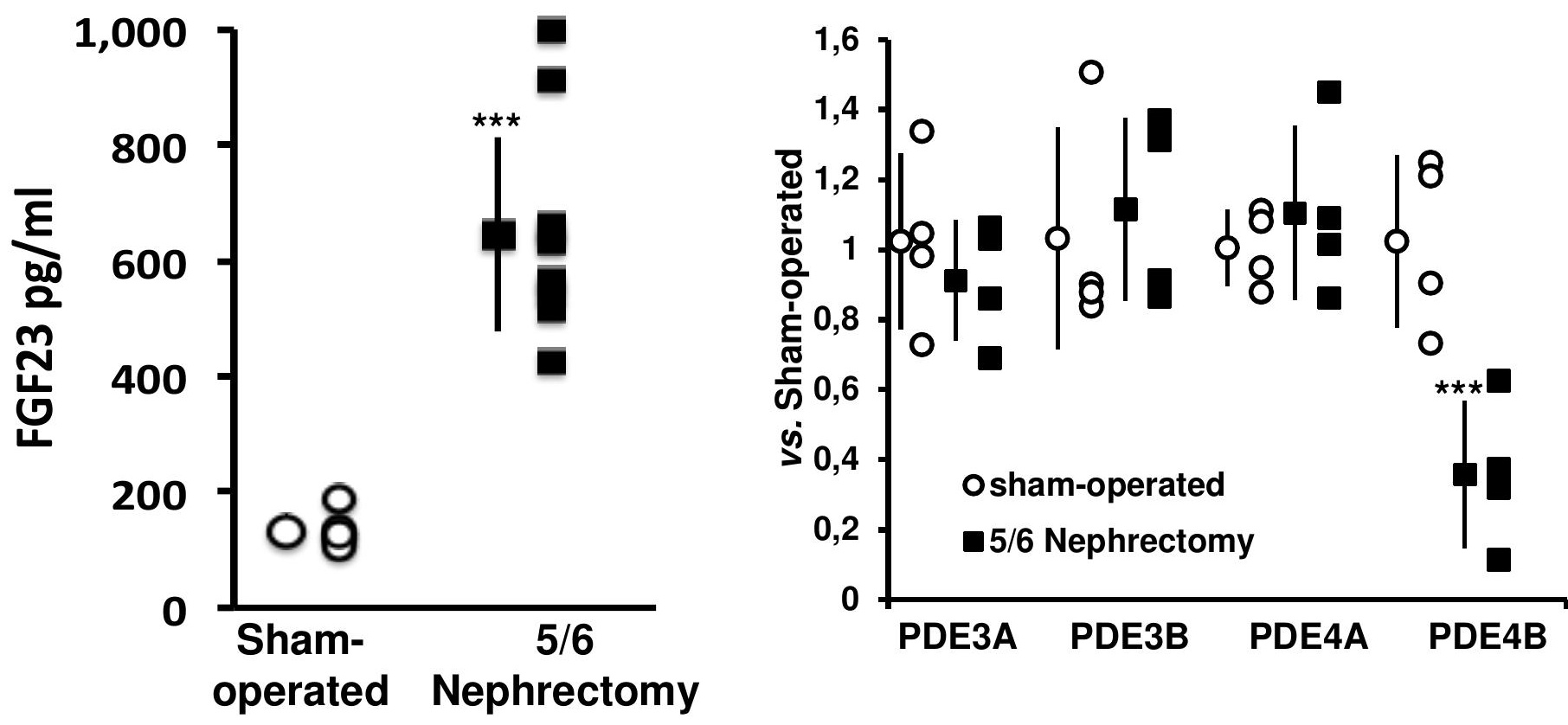

E

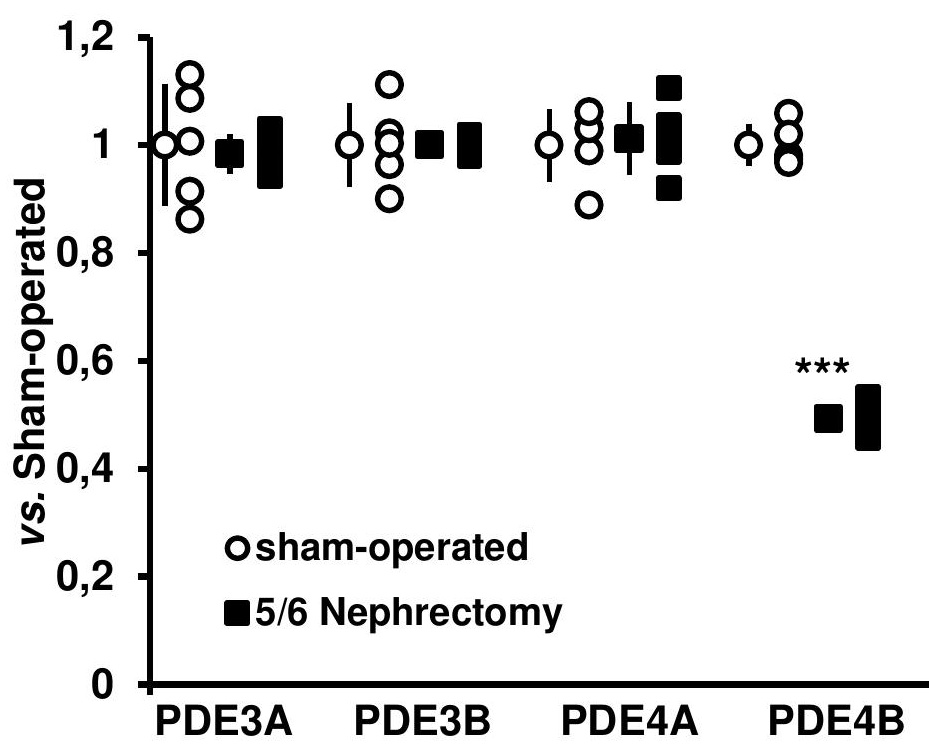




\section{SUPPLEMENTARY DATA}

Fibroblast Growth Factor 23 decreases PDE4 expression in heart increasing the risk of cardiac arrhythmia, Klotho opposes these effects

Marta Lindner*, Hind Mehel*, Amandine David*, Christine Leroy*, Martine Burtin*, Gérard Friedlander*§†, Fabiola Terzi*, Delphine Mika\#, Rodolphe Fischmeister\#, and Dominique Prié^§ł

\section{Detailed Methods}

All experiments were carried out according to the European Community guiding principles in the care and use of animals (2010/63/UE, 22 September 2010), the local Ethics committee (CEEA26 CAPSud) guidelines and the French decree $n^{\circ} 2013-118$, 1st February 2013 on the protection of animals used for scientific purposes (JORF $\mathrm{n}^{\circ} 0032,7$ February 2013 p2199, text $\mathrm{n}^{\circ} 24$ ). Animal experiments were approved by the French Ministry of Agriculture (prefectural agreement $\mathrm{N}^{\circ} 2016-108$ and agreement to our animal facility $\mathrm{N}^{\circ} \mathrm{C}$ 92-019-01).

\section{Isolation and culture of ARVMs}

Male Wistar rats $(250-300 \mathrm{mg})$ were subjected to anaesthesia by intraperitoneal injection of pentothal $(150 \mathrm{mg} / \mathrm{kg}$ ) and hearts were excised rapidly. Individual ARVMs were obtained by retrograde perfusion through the ascending aorta using Langendorff apparatus as described previously ${ }^{1}$. For enzymatic dissociation, the hearts were perfused at a constant flow of $6 \mathrm{ml} / \mathrm{min}$ at $37^{\circ} \mathrm{C}$ with a $\mathrm{Ca}^{2+}$-free Ringer solution containing (in $\mathrm{mM}$ ): $\mathrm{NaCl} 117, \mathrm{KCl} 5, \mathrm{NaHCO}_{3} 4.4, \mathrm{KH}_{2} \mathrm{PO}_{4} 1.5, \mathrm{MgCl}_{2}$ 1.7, D-glucose 11.7, Na-phospocreatine 10, taurine 20 and 4-(2-hydroxyethyl)piperazine-1ethanosulfonic acid (HEPES) 21, pH 7.1 during $2 \mathrm{~min}$, followed by a perfusion at 4 $\mathrm{mg} / \mathrm{mL}$ for $45 \mathrm{~min}$ with the same solution containing $1 \mathrm{mg} / \mathrm{mL}$ of collagenase $A$ (Roche Diagnostics $\mathrm{GmbH}$, Mannheim, Germany). The ventricles were then separated from atria, finely chopped and gently agitated to dissociate individual cells. The resulting cell suspension was filtered, and the cells were allowed to settle down. The supernatant was discarded and cells re-suspended two more times with Ringer solution at increasing $\left[\mathrm{Ca}^{2+}\right]$ from 20 to $100 \mu \mathrm{M}$. Freshly isolated cells were suspended in minimal essential medium (MEM: Sigma, St Louis, MO, USA) supplemented with $2.5 \%$ of fetal 
bovine serum (FBS, Invitrogen, Cergy-Pontoise, France), 1\% penicillin-streptomycin, $20 \mathrm{mM}$ HEPES and plated on $35 \mathrm{~mm}$ laminin-coated culture dishes $(10 \mu \mathrm{g} / \mathrm{mL})$. ARVMs were left to adhere for $1 \mathrm{~h}$ in a $95 \% \mathrm{O}_{2}, 5 \% \mathrm{CO}_{2}$ atmosphere at $37^{\circ} \mathrm{C}$, before the medium was replaced by FBS-free MEM and cells were treated with appropriate combinations and concentrations of FGF23, sKlotho, CspA, the FGFR antagonist (PD173074), noradrenaline, phenylephrine or FGF2.

\section{Production of FGF23 and sKlotho.}

A plasmid containing the human FGF23 cDNA encoding amino acids 1 to 251 of the intact peptide was expressed in Chinese hamster ovary cells. FGF23 protein, tagged with c-Myc, was purified from the medium using an anti-c-Myc agarose column purification procedure (Pierce ${ }^{\mathrm{TM}}$ Anti-c-Myc Agarose Thermo Scientific ${ }^{\top \mathrm{M}}$, Waltham, MA, USA). FGF23 concentration was determined using the iFGF23 immuno-chemiluminescent sandwich assay developed by DiaSorin (Saluggia, Italy) as previously described ${ }^{2}$.

HEK cells were stably transfected with a plasmid encoding amino acid 1 to 986 that represents the circulating or soluble form of aKlotho (sKlotho). sKlotho was released in the supernatant, the size of the protein was controlled by western blot. The concentration of sKlotho was determined with the IBL Elisa kit (Human soluble $\alpha$-Klotho Assay Kit code No. 27998 - IBL, Japan).

\section{Cell extracts and Western Blot analysis.}

ARVMs treated with appropriate combination with FGF23 $(6 \mathrm{ng} / \mathrm{ml})$, sKlotho $(0.95$ $\mathrm{ng} / \mathrm{ml})$, CspA $(1 \mu \mathrm{M})$ and phenylephrine $(50 \mu \mathrm{M})$ were lysed in cold RIPA (RadioImmunoprecipation Assay) lysis buffer containing (in mM): Tris- $\mathrm{HCl} 50$ (pH 7.4), NaCl 150, EDTA 2, NP40 1\%, DOC 1\%, SDS $0.1 \%$ supplemented with a protease inhibitor (Complete mini EDTA-free, Roche) and a phosphatase inhibitor (PhosphoSTOP, Roche Diagnostics, Gmbh, Mannheim, Germany) mixtures. Lysates were centrifuged for $10 \mathrm{~min}$ at $10000 \mathrm{~g}$ and at $4^{\circ} \mathrm{C}$, and the supernatant assayed for protein concentration using a FBS gradient. Protein samples prepared from isolated ARVMs were separated in denaturating acrylamide gels and subsequently transferred onto PVDF membranes. After blocking the membrane with $5 \%$ skimmed milk (p-PLB, PLB, p-RyR, RyR, SERCA 2a, TRPC6, FGFR1, FGFR3, FGFR4, PDEs, p-ERK, ERK, p-Akt, Akt, calsequestrin) or $5 \%$ BSA blocking buffer ( $\mathrm{p}-\mathrm{PLCY} 1, \mathrm{PLC} 1$ ) the incubation with antiCalsequestrin (1/2500, Affinity Bioreagents), anti-phosphorylated PLB at Ser16 (1/500, Badrilla), anti-phosphorylated PLB at Thr17 (1/500, Badrilla), anti-total PLB (1/500, Santa Cruz), anti-phosphorylated RyR at Ser2808 (1/1000, Badrilla), antiphosphorylated RyR at Ser2814 (1/1000, Badrilla), anti-total RyR (1/2000, Santa Cruz), anti-TRPC6 (1/1000, Merck Millipore), anti SERCA 2a (1/200, Santa Cruz), antiFGFR1 (1/1000, Abcam), anti-FGFR3 (1/1000, Abcam), anti-FGFR4 (1/1000, Abcam), anti-phosphorylated ERK1/2 at Thr202/Tyr204 (1/1000, Cell Signaling), anti-total ERK1/2 (1/1000, Cell Signaling), anti-phosphorylated PLCY1 at Tyr783 (1/1000, Cell Signaling), anti-total PLCY1 (1/1000, Cell Signaling), anti-phosphorylated Akt Ser473 (1/1000, Cell Signaling), anti-phosphorylated Akt Thr308 (1/1000, Cell Signaling), anti- 
total Akt (1/1000, Cell Signaling), anti-phosphodiesterase type 4A (1/5000) and type 4B (1/1000, the antibodies anti all PDE4 isoforms were kindly provided by Prof. Marco Conti, University of California, USA), anti-phosphodiesterase type 3A (1/1000, kindly provided by Dr Chen Yan, University of Rochester Medical Center, USA) and antiphosphodiesterase type 3B (1/1000, kindly provided by Dr Alessandra Ghigo, University of Torino, Italy) was carried out over night at $4^{\circ} \mathrm{C}$. After incubation with appropriate secondary antibodies for $1 \mathrm{~h}$, proteins were visualized by enhanced chemoluminescence and quantified with Quantity One software (Biorad, Hercules, CA, USA).

\section{Real-time PCR.}

Total RNA was isolated by utilizing Trizol reagent (Invitrogen) and the purity and concentration of RNA was detected by UV spectrophotometer. The values of OD260/OD280 of RNA samples were all in normal range (1.5 - 2.0). $1 \mu \mathrm{g}$ of RNA per samples was taken to generate cDNA (iScript cDNA Synthesis Kit, BioRad, Hercules, CA, USA) according to the manufactures guidelines. The relative amounts of PDE3A, PDE3B, PDE4A and PDE4B mRNA transcripts were quantified by real time PCR (SYBR Green/ROX qPCR, Master Mix, Fermentas, Waltham, MA, USA). Details of primers are provided in Supplementary Table 2. Reactions were conducted in a 96well Thermal Cycler (Applied Biosystems, Foster City, CA, USA). The mRNA levels were normalized to those of YWHAZ and Rpl32.

\section{cAMP measurements by FRET.}

ARVMs were infected with an adenovirus encoding the Epac-S ${ }^{H 187}$ CAMP-FRET probe (kindly provided by Dr. Kees Jalink, Cancer Institude, Amsterdam, Netherlands ${ }^{3}$ ) for 48h. Twenty four hours after adenoviral infection, cells were appropriate treated with FGF23 $(6 \mathrm{ng} / \mathrm{ml})$, soluble Klotho $(0.95 \mathrm{ng} / \mathrm{ml})$ and/or CspA $(1 \mu \mathrm{M})$ for an additional 24 $\mathrm{h}$. Thereafter, the cells were washed once and maintained in a physiological buffer containing (in $\mathrm{mM}$ ): $\mathrm{NaCl} 144, \mathrm{KCl} 5.4, \mathrm{CaCl}_{2} 1.8, \mathrm{MgCl}_{2} 1.8$ and HEPES 20, $\mathrm{pH} 7.4$ at room temperature. ISO at concentration of $30 \mathrm{nM}$ was applied briefly (15 s). Images were captured every $5 \mathrm{~s}$ using the $\times 40$ oil immersion objective of an inverted microscope (Nikon) connected to a CoolSNAP-HQ2 CCD-camera (Visitron System, Pullheim, Germany) controlled by the Metafluor Software (Molecular Devices). Cyan Fluorescent Protein (CFP) was excited for $300 \mathrm{~ms}$ by a Xenon lamp (Nikon) using a 440/20 BP filter and a 455 LP dichroic mirror. Dual-emission imaging of CFP and Yellow Fluorescent Protein (YFP) was performed using a Dual-View emission splitter equipped with a 510 LP dichroic mirror and BP filters 480/30 and 535/25 nm, respectively. The YFP/CFP emission ratio upon $436 \mathrm{~nm}$ excitation (filters YFP $535 \pm 15$ $\mathrm{nm}$, CFP $480 \pm 20 \mathrm{~nm}$ ) was measured. After each measurement, emission values were corrected for bleed through of CFP into YFP channel. The imaging data was analyzed with Excel. All experiments were performed at room temperature. 


\section{Measurements of SR $\mathrm{Ca}^{2+}$ leak and SR $\mathrm{Ca}^{2+}$ load.}

Isolated ARVMs treated with FGF23 $(6 \mathrm{ng} / \mathrm{ml})$ for $24 \mathrm{~h}$ were loaded with $1 \mu \mathrm{M}$ Fura-2AM (Invitrogen, Carlsbad, CA, USA) for $15 \mathrm{~min}$ in a Ringer solution containing (in $\mathrm{mM}$ ): $\mathrm{KCl} 5.4, \mathrm{NaCl} 121.6, \mathrm{Na}$-pyruvate $5, \mathrm{NaHCO}_{3} 4.013, \mathrm{NaH}_{2} \mathrm{PO}_{4} 0.8, \mathrm{CaCl}_{2} 1,8, \mathrm{MgCl}_{2}$ 1.8, glucose 5 and HEPES $10(\mathrm{pH} 7.4$ with $\mathrm{NaOH}$ ) at room temperature for $15 \mathrm{~min}$.

$\mathrm{SR} \mathrm{Ca}^{2+}$ leak and load were measured as previously described ${ }^{4}$. Fura-2 loaded ventricular myocytes were paced by field stimulation at $0.5 \mathrm{~Hz}$ in normal Ringer for few minutes until cellular $\mathrm{Ca}^{2+}$ transients reached a steady state. Directly after the last pulse, normal Ringer was substituted for $30 \mathrm{~s}$ by a $0 \mathrm{Na}^{+} / \mathrm{OCa}^{2+}$ Ringer in which $\mathrm{Na}^{+}$ was replaced by $\mathrm{Li}^{+}$and supplemented with $10 \mathrm{mM}$ EGTA. This condition allowed measuring intracellular $\mathrm{Ca}^{2+}$ levels in a closed system without trans-sarcolemmal $\mathrm{Ca}^{2+}$ fluxes. Then, the cell was switched back to normal Ringer and paced at $0.5 \mathrm{~Hz}$ until $\mathrm{Ca}^{2+}$ transient amplitude and sarcomere shortening reached steady-state. Again, following the last pulse, cells were perfused for $30 \mathrm{~s}$ with a $0 \mathrm{Na}^{+} / \mathrm{OCa}^{2+}$ solution including $1 \mathrm{mM}$ of the RyR2 inhibitor, tetracaine. As a consequence, $\mathrm{SR} \mathrm{Ca}{ }^{2+}$ leak into the cytoplasm was prevented. SR $\mathrm{Ca}^{2+}$ leak was estimated as a difference between the Fura-2 ratio recorded at the end of the $0 \mathrm{Na}^{+} / \mathrm{CCa}^{2+}$ Ringer perfusion with and without tetracaine. At the end of this protocol, tetracaine was washed out for at least 60 seconds and caffeine $(10 \mathrm{mM})$ was applied to evaluate the total SR Ca ${ }^{2+}$ content.

$\mathrm{SR} \mathrm{Ca}^{2+}$ leak was measured by subtracting the ratio of fluorescence recorded in steady-state in $0 \mathrm{Na}^{+} / 0 \mathrm{Ca}^{2+}$ Ringer with tetracaine from the ratio recorded in steadystate in $0 \mathrm{Na}^{+} / 0 \mathrm{Ca}^{2+}$ Ringer without tetracaine. SR Ca ${ }^{2+}$ load was estimated by dividing the amplitude of the caffeine-induced twitch (difference between the peak ratio obtained with caffeine and the diastolic ratio measured before tetracaine treatment) by the diastolic ratio. All parameters were calculated using lonWizard 6 (IonOptix, Westwood, MA, USA).

\section{Measurement of cell surface area.}

To determine the cellular hypertrophy, we measured cell surface area. Twenty four hours after appropriate treatment with increasing concentrations of FGF23 $(0.6,1.2$ and $6 \mathrm{ng} / \mathrm{mL}$ ), noradrenaline (NOR $10 \mu \mathrm{M}$ ) or recombinant FGF2 $(6 \mathrm{ng} / \mathrm{mL})$ images of treated cells were taken from different fields of each culture dish with a cooled charged coupled (CCD) camera (Sensicam PE ; PCO, Kelheim, Germany) using the 20x objective of a Nikon TE 300 inverted microscope and $488 \mathrm{~nm}$ illumination. Surface area of individual myocytes was determined using Image $\mathrm{J}$ software (Wayne Rasband, National Institutes of Health, USA). Data are normalized to control cells (with control medium) and presented as \% increase over control condition.

\section{Induction of RI by nephrectomy $5 / 6$.}

Eight-week-old mice were randomized to either $5 / 6$ nephrectomy $(5 / 6 \mathrm{Nx})$ or sham surgery. Surgery and euthanasia of animals were performed under general anesthesia by intraperitoneal injection of ketamine $(160 \mathrm{mg} / \mathrm{kg})$ and xylazine $(8 \mathrm{mg} / \mathrm{kg})$. Briefly, an abdominal midline incision of the skin and muscles was made and the left kidney was decapsulated to avoid adrenal and ureter damage after which the upper and lower 
poles were removed by an electro coagulator. In the same procedure, the right kidney was removed after ligation of the renal blood vessels and the ureter. In control mice, sham surgery was performed, which included decapsulation of both kidneys, but no removal of kidney tissue. After surgery, all mice received subcutaneous injections of postoperative analgesia for two consecutive days. Six weeks after surgery, the urine and blood plasma were collected.

\section{FGF23 measurements in plasma samples.}

Blood was collected from mice subjected to $5 / 6 \mathrm{Nx}$ or sham-operated mice by heart puncture at the end of experimental protocol. Blood was put into EDTA-coagulated tubes and centrifuged for $10 \mathrm{~min}$ at $1500 \mathrm{~g}$ at $4^{\circ} \mathrm{C}$. Plasma samples were stored at $80^{\circ} \mathrm{C}$. Circulating FGF23 concentrations were measured in duplicate using an ELISA assay (Immutopics International, San Clemente, CA, USA), according to the manufacturers protocol.

1. Verde I, Vandecasteele G, Lezoualc'h F, Fischmeister R. Characterization of the cyclic nucleotide phosphodiesterase subtypes involved in the regulation of the Ltype $\mathrm{Ca}^{2+}$ current in rat ventricular myocytes. British journal of pharmacology 1999;127:65-74.

2. Souberbielle JC, Prie D, Piketty ML, et al. Evaluation of a New Fully Automated Assay for Plasma Intact FGF23. Calcified tissue international 2017;101:510-8.

3. Klarenbeek JB, Goedhart J, Hink MA, Gadella TW, Jalink K. A mTurquoisebased CAMP sensor for both FLIM and ratiometric read-out has improved dynamic range. PloS one 2011;6:e19170.

4. Shannon TR, Ginsburg KS, Bers DM. Quantitative assessment of the SR $\mathrm{Ca}^{2+}$ leak-load relationship. Circulation research 2002;91:594-600. 


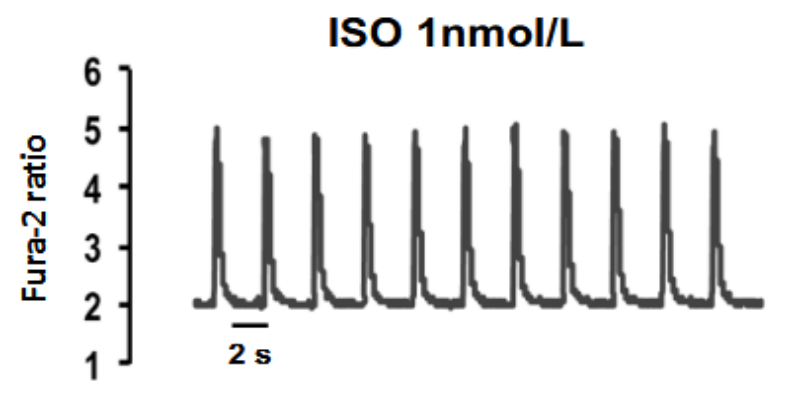

ISO 1 nmol/L + FGF23 6ng/ml

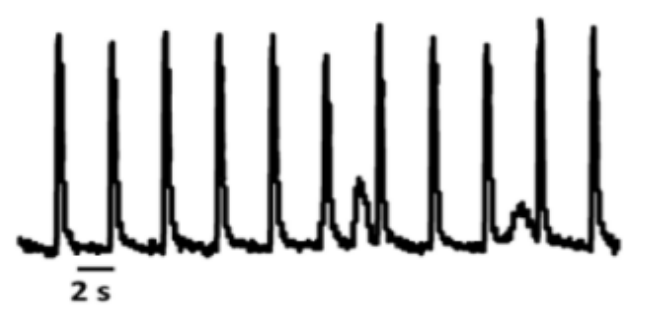

Figure S1. FGF23-treated ARVMs show a higher susceptibility to arrhythmic events. A: Representative traces of $\mathrm{Ca}^{2+}$ transients in Fura-2 loaded ARVMs paced at $0.5 \mathrm{~Hz}$ in the presence of ISO $(1 \mathrm{nM})$ from a cell cultured in control medium (left) or with FGF23 for $24 \mathrm{~h}$ (right). 
A

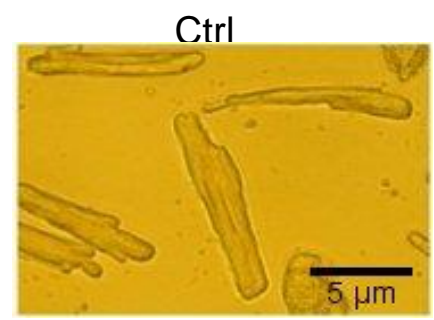

FGF23 6na/ml

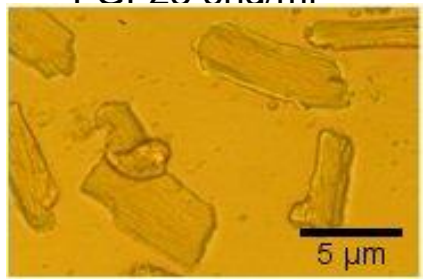

B

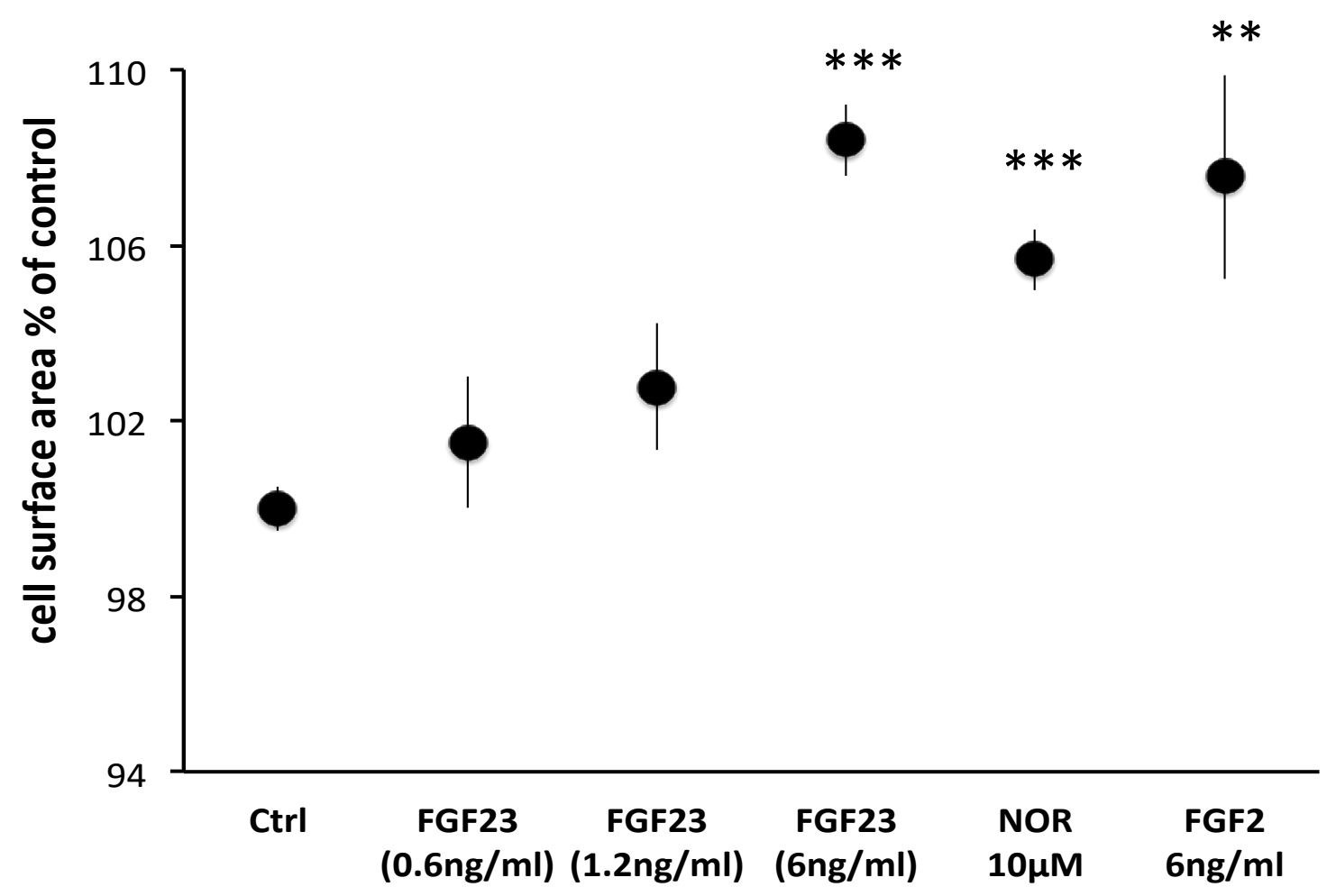

Figure S2. FGF23 induces an increase in cell surface area. A: Representative images of ARVMs treated for $24 \mathrm{~h}$ with FGF23 $(6 \mathrm{ng} / \mathrm{ml})$ or vehicle (Ctrl). B: ARVMs treated with control medium (Ctrl) or increasing concentrations of FGF23, noradrenaline (NOR) or FGF2 as a positive control. All data are presented as mean ( \pm SEM), statistical significance was determined by one-way Anova followed by Dunnett's comparison test, ${ }^{* *} \mathrm{p}<0.001,{ }^{* * *} \mathrm{p}<0.0001$ vs. control ( $\mathrm{N}=5$ rats, $\mathrm{n}=77-99$ cells). 


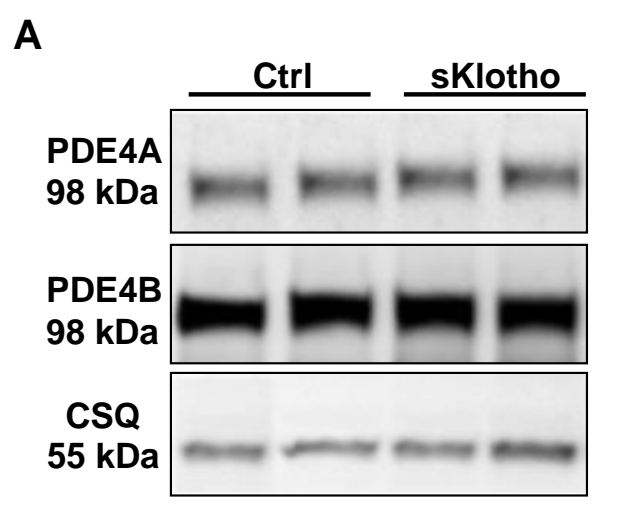

B

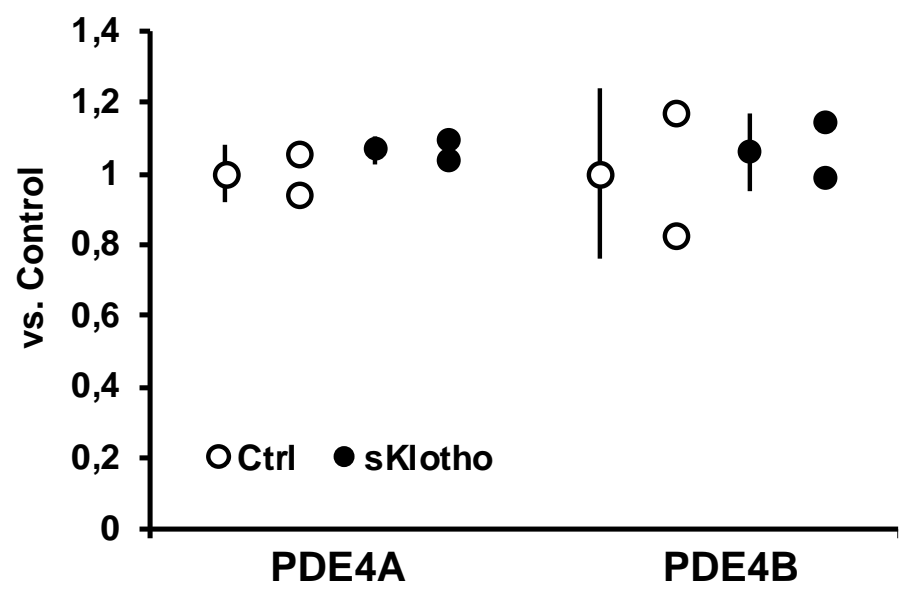

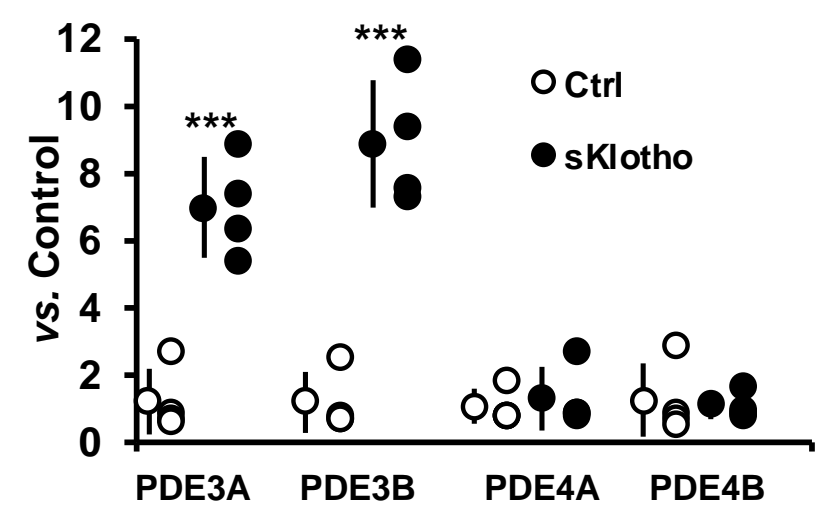
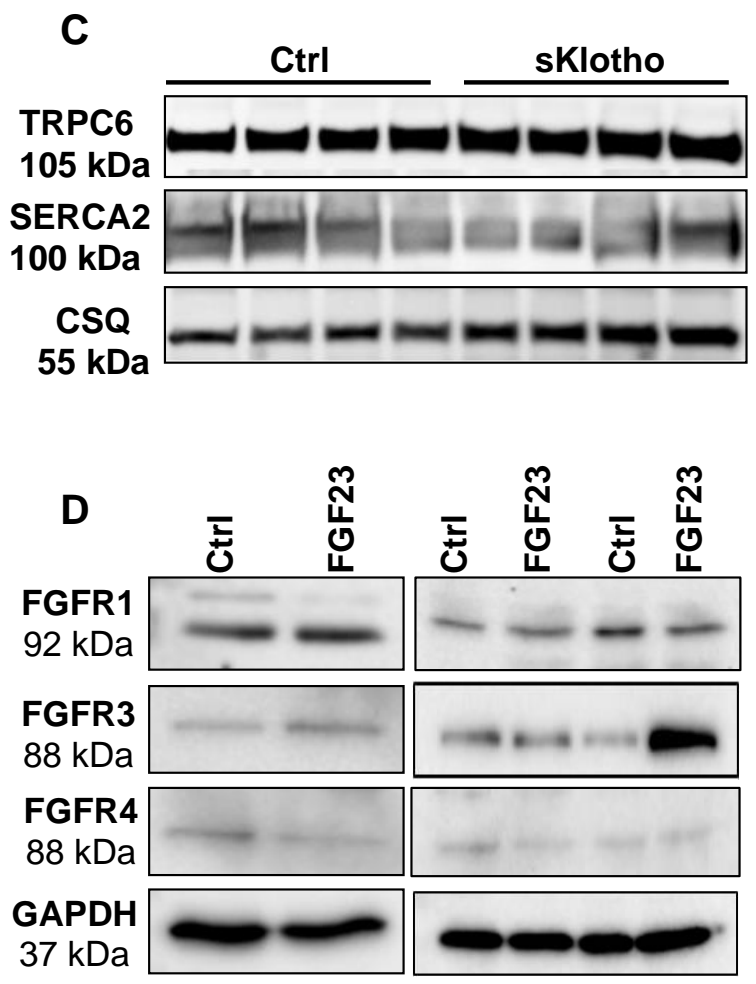
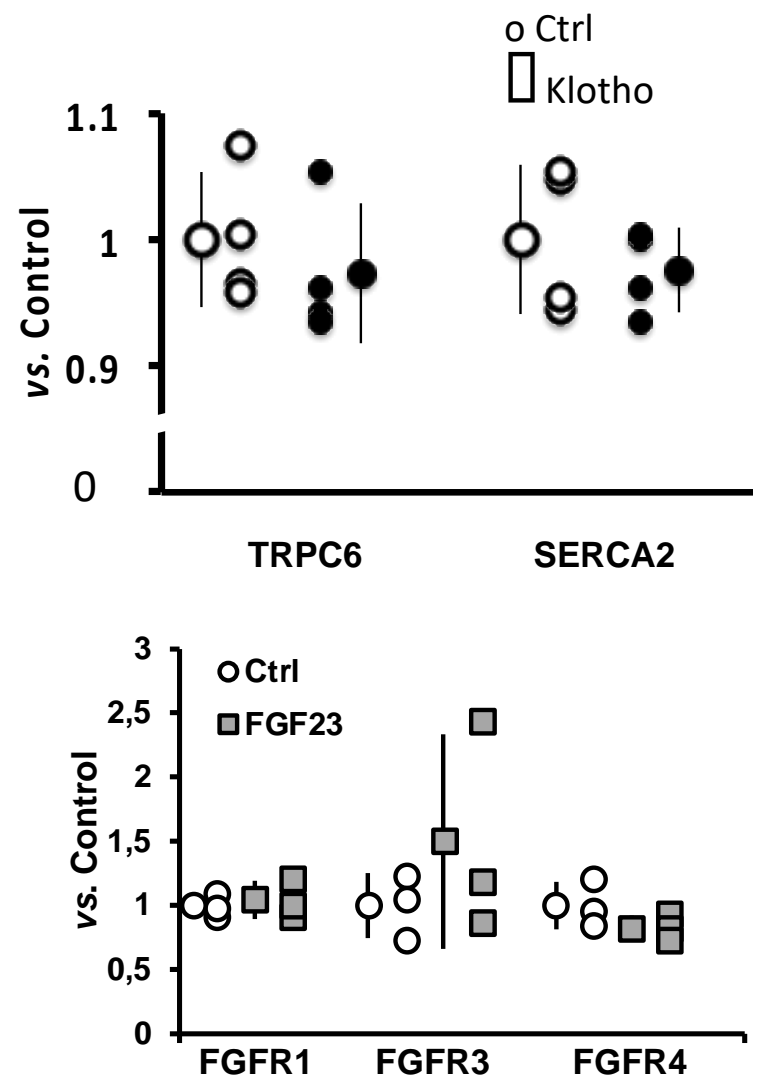

Supplementary figure 3 
Figure S3. sKlotho does not affect TRPC6, SERCA2, PDE4A and PDE4B expression. Expression pattern of FGFR types and phosphorylation of ERK ventricular myocytes. $A$ : sKlotho does not change PDE4 and PDE4B expression level. Left panel shows the immunoblot and right panel its quantification. Protein expression was normalized to calsequestrin (CSQ). Data are presented as a fold change from the control (Ctrl) levels ( \pm SEM). The protein level was not different between groups ( $\mathrm{N}=2$ rats per group). B: sKlotho increases mRNA level of PDE3A and PDE3B. and does not modify PDE4A, PDE4B mRNA levels. mRNA expression was analyzed with qRT-PCR and normalized. Data are presented as a fold change from the control (Ctrl) levels $( \pm S E M)$. Statistical significance was determined by Student's test, ${ }^{* * *}$ $\mathrm{p}<0.001$ vs. control ( $\mathrm{N}=4$ rats per group). C: sKlotho does not change expression level of TRPC6 and SERCA. Left panel shows the immunoblot and right panel its quantification. Protein expression was normalized to calsequestrin (CSQ). Data are presented as a fold change from the control (Ctrl) levels $( \pm S E M)$. The protein level was not different between groups ( $\mathrm{N}=4$ rats per group). D: Three types of FGFR are expressed in the cardiomyocytes (FGFR1, FGFR3, FGFR4). Left panel shows the immunoblot and right panel its quantification. Protein expression was normalized to GAPDH protein. Data are presented as a fold change from the control (Ctrl) levels $( \pm$ SEM). No difference was observed after treatment with FGF23 compared to control group. ( $\mathrm{N}=3$ rat per group). 


\begin{tabular}{|c|c|c|}
\hline Target & NCBI Reference Sequence & $\begin{array}{c}\text { Primer forward 5' '> 3' } \\
\text { Primer reverse 5' '> 3' }\end{array}$ \\
\hline PDE3A & Rat & 5' ACCTCCCTGCCCTGCATAC 3' \\
& NM_017337 & 5' CCTCTCTTGTGGTCCCATTC 3' \\
\hline PDE3B & Rat & 5' GTGGCTACAAATGCACCTCA 3' \\
& 5M_017229 & 5' CTGGGCGAGAAAGATACAGA 3' \\
\hline PDE4A & Rat & 5' CGTCAGTGCTGCGACAGTC 3' \\
& NM_013101 & 5' CCAGCGTACTCCGACACACA 3' \\
\hline PDE4B & Rat & 5' GATGAGCAGATCAGGGAACC 3' \\
& Mouse & 5' GATGGGATTTCCACATCGTT 3' \\
\hline PDE4A & NM_019798.5 & 5' CCAGGTCTCAGAGTACATTTCCAA 3' \\
& 5' CGATGGGATCTCCACTTCGT 3' \\
& (Mougenot et al, Cardiovasc Res, 2019) & \\
\hline PDE4B & Mouse & 5' GTCAGGCTCCAGTCTCCAGAGT 3' \\
& NM_019840.2 & 5' GCGTCTCCATTGCTAGTTTCTGAT 3' \\
& (Mougenot et al, Cardiovasc Res, 2019) & \\
\hline YWHAZ & Rat/mouse & 5' AGACGGAAGGTGCTGAGAAA 3' \\
& NM_013011/NM_011740 & 5' GAAGCATTGGGGATCAAGAA 3' \\
\hline Rpl32 & Rat/mouse & 5' GCTGCTGATGTGCAACAAA 3' \\
& NM_013226/NM_172086 & 5' GGGATTGGTGACTCTGATGG 3' \\
\hline
\end{tabular}

Table S1: qRT-PCR primer sequences for SYBR green technology. 


\begin{tabular}{|c|c|c|c|}
\hline \multirow[b]{3}{*}{ Laboratory test } & \multicolumn{2}{|c|}{ Group } & \multirow[b]{3}{*}{$\mathbf{P}$} \\
\hline & $\begin{array}{l}\text { Sham- } \\
\text { operated }\end{array}$ & $\begin{array}{c}\text { Subtotal } \\
\text { Nephrectomy }\end{array}$ & \\
\hline & \multicolumn{2}{|c|}{$\begin{array}{c}\text { (Mean } \pm \text { standard error of } \\
\text { mean) }\end{array}$} & \\
\hline Body weight $(\mathrm{g})$ & $28.7 \pm 1.4$ & $22.8 \pm 0.9$ & 0.00178 \\
\hline Remnant kidney weight (mg) & $154.0 \pm 6.9$ & $281.5 \pm 18.3$ & $<0.001$ \\
\hline Heart weight $(\mathrm{mg})$ & $119.0 \pm 4.4$ & $134.7 \pm 4.8$ & 0.0475 \\
\hline Creatinine in plasma $(\mathrm{mmol} / \mathrm{L})$ & $10.37 \pm 1.00$ & $29.90 \pm 4.14$ & 0.0039 \\
\hline Creatinine in urine $(\mathrm{mmol} / \mathrm{L})$ & $5.06 \pm 0.31$ & $1.20 \pm 0.15$ & $<0.001$ \\
\hline Microalbumine in urine (mg/L) & $16.5 \pm 7.2$ & $2857 \pm 811$ & 0.036 \\
\hline Protein in urine $(\mathrm{g} / \mathrm{L})$ & $7.6 \pm 2.8$ & $12.4 \pm 3.2$ & 0.355 \\
\hline Sodium in urine $(\mathrm{mmol} / \mathrm{L})$ & $182 \pm 23$ & $42 \pm 3$ & $<0.001$ \\
\hline Potassium in urine (mmol/L) & $275 \pm 16$ & $47 \pm 5$ & $<0.001$ \\
\hline Chloride in urine $(\mathrm{mmol} / \mathrm{L})$ & $338 \pm 34$ & $62 \pm 4$ & $<0.001$ \\
\hline $\begin{array}{c}\text { Microalbumine urine/creatinine } \\
\text { plasma (mg/L) }\end{array}$ & $3.0 \pm 1.2$ & $2203 \pm 454$ & 0.00639 \\
\hline $\begin{array}{l}\text { Protein urine/creatinine plasma } \\
\qquad(\mathrm{g} / \mathrm{L})\end{array}$ & $1.4 \pm 0.4$ & $9.8 \pm 1.8$ & 0.00968 \\
\hline $\begin{array}{l}\text { Sodium urine/creatinine plasma } \\
(\mathrm{mmol} / \mathrm{L})\end{array}$ & $36.8 \pm 5.4$ & $41.3 \pm 6.5$ & 0.672 \\
\hline $\begin{array}{c}\text { Potassium urine/creatinine } \\
\text { plasma }(\mathrm{mmol} / \mathrm{L})\end{array}$ & $54.8 \pm 3.5$ & $42.9 \pm 5.2$ & 0.164 \\
\hline $\begin{array}{l}\text { Chloride urine/creatinine plasma } \\
(\mathrm{mmol} / \mathrm{L})\end{array}$ & $68.1 \pm 8.2$ & $58.2 \pm 6.4$ & 0.387 \\
\hline
\end{tabular}

Table S2: Characteristic of sham-operated mice and mice submitted to subtotal nephrectomy. All parameters of plasma and urine were compared to sham-operated mice. Statistical significance was determined by Student's test to compare the 2 groups and $p$ values are presented in the table ( $\mathrm{N}=6-11$ mice per group). 